\title{
Plant leaf wax biomarkers capture gradients in hydrogen isotopes of precipitation from the
} Andes and Amazon

Sarah J. Feakins* ${ }^{* a}$; Lisa Patrick Bentley ${ }^{\mathrm{b}}$; Norma Salinas ${ }^{\mathrm{b}, 1}$; Alexander Shenkin ${ }^{\mathrm{b}}$; Benjamin Blonder ${ }^{\mathrm{b}}$; Gregory R. Goldsmith ${ }^{\mathrm{b}}$; Camilo Ponton ${ }^{\mathrm{a}}$; Lindsay J. Arvin ${ }^{\mathrm{a}}$; Mong Sin $\mathrm{Wu}^{\mathrm{a}}$; Tom Peters ${ }^{\text {s }}$; A. Joshua West ${ }^{\mathrm{a}}$; Roberta E. Martin ${ }^{\mathrm{c}}$; Brian, J. Enquist ${ }^{\mathrm{d}}$; Gregory, P. Asner ${ }^{\mathrm{c}}$; Yadvinder Malhi $^{\mathrm{b}}$

${ }^{a}$ Department of Earth Sciences, University of Southern California, Los Angeles, CA 90089, USA.

${ }^{\mathrm{b}}$ Environmental Change Institute, School of Geography and the Environment, University of Oxford, Oxford, OX1 3QY, UK.

${ }^{\mathrm{c}}$ Department of Global Ecology, Carnegie Institution for Science, Stanford, CA 94305, USA.

${ }^{\mathrm{d}}$ Department of Ecology and Evolutionary Biology, University of Arizona, AZ 85721, USA. 3

(1)

(6)

17

8

*Corresponding author: Sarah J. Feakins, email: feakins@usc.edu, phone: 2137407168

${ }^{1}$ Permanent address: Seccion Química, Pontificia Universidad Católica del Peru, Peru.

\section{Author Contribution Statement}

S.J.F planned and designed the leaf wax and plant water study; Y.M. conceived the field campaign; Y.M. B.J.E., G.P.A., L.P.B., N.S., G.R.G. and A.S., designed the CHAMBASA field campaign; A.J.W and S.J.F. designed the stream and precipitation sampling. S.J.F. performed plant water extractions and leaf wax isotopic analyses; M.S.W., T.P., L.J.A., analyzed leaf wax concentrations; C.P. sampled streams and analyzed stream water and precipitation. L.P.B., N.S., A.S., B.B., G.R.G., conducted CHAMBASA fieldwork. R.E.M. led taxonomy. S.J.F., L.P.B., A.S., B.B., C.P., M.S.W., T.P., analyzed aspects of data and S.J.F. wrote the manuscript. 


\section{Abstract}

32 Plant leaf waxes have been found to record the hydrogen isotopic composition of precipitation 33 and are thus used to reconstruct past climate. To assess how faithfully they record hydrological

34 signals, we characterize leaf wax hydrogen isotopic compositions in forest canopy trees across a 35 highly biodiverse, $3 \mathrm{~km}$ elevation range on the eastern flank of the Andes. We sampled the 36 dominant tree species and assessed their relative abundance in the tree community. For each tree

37 we collected xylem and leaf samples for analysis of plant water and plant leaf wax hydrogen 38 isotopic compositions. In total, 176 individuals were sampled across 32 species and 5 forest plots

39 that span the gradient. We find both xylem water and leaf wax $\delta \mathrm{D}$ values of individuals correlate $40 \quad\left(\mathrm{R}^{2}=0.8\right.$ and $\mathrm{R}^{2}=0.3$ respectively) with the isotopic composition of precipitation (with an 41 elevation gradient of $-21 \% \mathrm{~km}^{-1}$ ). Minimal leaf water enrichment means that leaf waxes are 42 straightforward recorders of the isotopic composition of precipitation in wet climates. For these 43 tropical forests we find the average fractionation between source water and leaf wax for $\mathrm{C}_{29} n$ 44 alkanes, $-129 \pm 2 \%$ (s.e.m., $n=136$ ), to be indistinguishable from that of temperate moist 45 forests. For $\mathrm{C}_{28} n$-alkanoic acids the average fractionation is $-121 \pm 3 \%$ (s.e.m., $n=102$ ). 46 Sampling guided by community assembly within forest plots shows that integrated plant leaf 47 wax hydrogen isotopic compositions faithfully record the gradient of isotopes in precipitation 48 with elevation $\left(\mathrm{R}^{2}=0.97\right.$ for $n$-alkanes and 0.60 for $n$-alkanoic acids $)$. This calibration study 49 supports the use of leaf waxes as recorders of the isotopic composition of precipitation in 50 lowland tropical rainforest, tropical montane cloud forests and their sedimentary archives.

51 Keywords: Andes; Amazon; biomarker; ecohydrology; hydrogen isotopes; leaf wax. 
53 Tropical forests are some of the most productive and diverse ecosystems on the planet. They are

54 significantly threatened by deforestation (e.g., Malhi et al., 2014b) and projected climate change

55 (Cox et al., 2004; Oyama and Nobre, 2003) including the possibility of changes in hydrological

56 cycling (Zelazowski et al., 2011). If we want to better monitor and track how hydroclimate

57 affects tropical forests, then the hydrogen and oxygen isotopic composition of water can provide

58 us with valuable insights, including into seasonality and precipitation amounts (Lee et al., 2009).

59 At the scale of the Amazon basin, the isotopic composition of precipitation is dependent upon

60 atmospheric circulation and rainout, as well as vapor recharge with transpiration from the forest

61 (Salati et al., 1979). Isotopes have the potential to be powerful tracers of change in the

62 ecosystem-atmosphere water cycle at the continental scale, particularly when sampling schemes

63 capture precipitation isotope gradients (Winnick et al., 2014). Uptake of water by plants leads to

64 the isotopic composition of precipitation being encoded in the hydrogen isotopic composition of

65 plant waxes, including those on tree leaves (Sachse et al., 2012). These waxes survive long

66 beyond the life of the plant to become molecular fossils or 'biomarkers' in geological archives

67 and are commonly used to reconstruct past hydrological conditions (Feakins et al., 2012;

68 Schefuss et al., 2005; Tierney et al., 2013).

69 Fundamental to this approach is the observation that the isotopic composition of source water

$70\left(\delta \mathrm{D}_{\mathrm{w}}\right)$, usually precipitation, is translated into that of leaf wax $\left(\delta \mathrm{D}_{\mathrm{wax}}\right)$ after a large 'apparent'

71 fractionation $\left(\varepsilon_{\text {app }}\right)$ the net effect of multiple fractionation steps (Sachse et al., 2012). The

72 biosynthetic fractionation $\left(\varepsilon_{\text {bio }}\right)$ associated with the synthesis of wax, comprises the major isotope

73 effect at c. $-160 \%$ (Sessions et al., 1999). While commonly assumed to be relatively invariant, 
$74 \varepsilon_{\text {bio }}$ does vary with the use of stored versus primary photosynthate such as across the growing

75 season (Newberry et al., 2015; Sessions, 2006). While $\varepsilon_{\text {bio }}$ may also vary between organisms and

76 ecosystems (Kahmen et al., 2013b), tropical forests are unknown in this regard. A secondary

77 effect on isotope fractionation is the net enrichment between precipitation and leaf water,

78 whether in soils (evaporation) or in the leaf (associated with processes of transpiration and

79 atmospheric vapor exchange; expressed as the enrichment of bulk leaf water over xylem water

$80 \varepsilon_{\mathrm{LW} / \mathrm{XW}}$ ) (Feakins and Sessions, 2010; Kahmen et al., 2013b; Kahmen et al., 2013a; Smith and

81 Freeman, 2006). As both processes are modulated by climate (including relative humidity and

82 temperature) and ecology (for example rooting strategies and monocot versus dicot leaves), this

83 motivates calibration in different climatic conditions and ecosystems.

84 Calibration studies of leaf wax hydrogen isotope systematics in living plants have included

85 temperate zones (Hou et al., 2007; Sachse et al., 2006; Tipple and Pagani, 2013), arid zones

86 (Feakins and Sessions, 2010; Kahmen et al., 2013b; Smith and Freeman, 2006) and high latitudes

87 (Shanahan et al., 2013; Wilkie et al., 2013), but not yet tropical forests. Leaf water model

88 predictions suggest that $\varepsilon_{\text {LW/Xw }}$ will be minimal in wet climates $<20 \%$ (Kahmen et al., 2013b;

89 West et al., 2008), a prediction that we directly test in this study with combined plant water and

90 wax measurements. A critical next step in understanding plant wax hydrogen isotope

91 biogeochemistry toward global calibration of the proxy is to establish how the hydrogen isotopic

92 composition of source water $\left(\delta \mathrm{D}_{\mathrm{w}}\right)$ translates into that of leaf wax $\left(\delta \mathrm{D}_{\mathrm{wax}}\right)$ in tropical forests,

93 including lowland rainforests and tropical montane broadleaf forests. Such studies of tropical

94 hydrogen isotope biogeochemistry will inform tropical paleoenvironmental interpretations.

95 1.1. Tropical rainforests 
96 The forests of the western Amazon are notably some of the most diverse ecosystems in the world

97 (Kreft and Jetz, 2007) which includes not only high species diversity (Ter Steege et al., 2010),

98 but also high diversity in plant functions (Silman, 2014). The absence of prior studies of

99 hydrogen isotopes in living plants in tropical lowland rainforest ecosystems leaves many open

100 questions, and not least of these is the overriding question about how well these proxy recorders

101 will work in the context of tropical climates and high biodiversity. Specific questions include

102 whether there are interspecies variations in plant water systematics (such as might be associated

103 with the physiology of the roots and leaves) that may impact plant water isotopic compositions

104 (Gao et al., 2015; Krull et al., 2006), or whether these physiological and plant water regulation

105 concerns are mitigated in high humidity, tropical climates? In the context of taxonomic diversity,

106 are there variations in biosynthetic fractionations that might be related to plant functional

107 differences (including differing metabolic pathways, use of stored carbohydrates and seasonality

108 of growth strategies)? To begin to collect data to address these and other questions, we set out to

109 collect a large ecosystem-scale survey of plant water and leaf wax isotopic compositions for tree

110 species from forest plots in a transect that extends through western Amazonian, lowland

111 rainforest and up through Andean tropical montane cloud forests.

\subsection{Tropical montane cloud forests}

113 Cloud forests are those forests that are frequently or persistently immersed in ground level cloud

114 (i.e. fog) and include lowland coastal forests such as the Redwoods of California (Dawson,

115 1998), but cloud forests are most widely distributed in tropical mountains with over 560

116 confirmed tropical montane cloud forest regions (Bruijnzeel et al., 2011). Estimates of the global

117 areal extent of tropical montane cloud forests range from $215000 \mathrm{~km}^{2}$, based on typical 
118 elevation distributions (800 to $3500 \mathrm{~m}$ elevation), to $2210000 \mathrm{~km}^{2}$, based on satellite estimates

119 of cloud extent (Bruijnzeel et al., 2011). In the Andes, cloud forest occurs between $~ 1500-3500$

$120 \mathrm{~m}$ asl (Bruijnzeel et al., 2011). Although less diverse than the lowland rainforests below, tropical

121 montane cloud forests (TMCF) are recognized as biodiversity 'hotspots', i.e. regions of notable

122 biodiversity that are under threat of habitat loss (Myers et al., 2000), whether due to deforestation

123 or changing cloud frequencies associated with temperature rise. This vulnerability is also of

124 concern downstream, given the role of these forest ecosystems in regulating catchment

125 hydrology (Viviroli et al., 2007). In terms of isotope biogeochemistry, it has been suggested that

126 cloud forests may have unique isotope systematics based on an evolved capacity for foliar water

127 uptake (Goldsmith et al., 2013). We expect to see isotopic signatures associated with the uptake

128 of fog waters that would suppress the D-enrichment of leaf waters during transpiration that has

129 been reported in low relative humidity environments (Feakins and Sessions, 2010). Plant water

130 and wax hydrogen isotope systematics in high precipitation $\left(2-5 \mathrm{~m} \mathrm{a}^{-1}\right)$ and sometimes cloud-

131 immersed forests (above $1500 \mathrm{~m}$ ) are assessed as part of this survey of tropical forests across a 3

$132 \mathrm{~km}$ elevation range.

\subsection{Elevation gradients}

134 Elevation transect studies uniquely capture a wide range of environmental conditions within a 135 relatively small spatial scale (Becker et al., 2007; Malhi et al., 2010). The 'altitude effect', i.e., 136 change in the isotopic composition of precipitation with elevation (Gonfiantini et al., 2001), 137 provides the opportunity to capture a large range of isotopic values. Like many other spatial 138 transects, elevation profiles sample shifts not only in the isotopic composition of precipitation 139 but also in other environmental parameters including mean annual temperature, the amount and 
seasonality of precipitation, relative humidity, cloud immersion frequency, ultraviolet radiation

141 and atmospheric pressure and partial pressures. These parameters contribute to vegetation

142 transitions and each may affect isotopic compositions. Other calibration studies comparing the

$143 \delta \mathrm{D}$ of precipitation and plant leaf wax biomarkers have included latitudinal, altitudinal and

144 continental transects of modern plants (Feakins and Sessions, 2010; Kahmen et al., 2013b;

145 Sachse et al., 2006; Smith and Freeman, 2006; Tipple and Pagani, 2013), soils (Bai et al., 2015;

146 Ernst et al., 2013; Jia et al., 2008; Peterse et al., 2009), lake sediments (Hou et al., 2008; Polissar

147 and Freeman, 2010; Sachse et al., 2004), and river sediments (Galy et al., 2011; Ponton et al.,

148 2014). Prior studies across elevation gradients have suggested that plant leaf wax hydrogen

149 isotopic compositions in soils or rivers do capture elevation gradients in the isotopic composition

150 of precipitation (Bai et al., 2015; Ernst et al., 2013; Galy et al., 2011; Jia et al., 2008; Luo et al.,

151 2011; Ponton et al., 2014), and this leaf wax method has been applied to ancient sediments to

152 reconstruct precipitation isotopes for paleoaltimetry (Hren et al., 2010; Polissar et al., 2009).

153 While the expected altitude effect has been shown in 6 species ( 2 conifers, 2 deciduous trees, 2

154 shrubs) growing between 2900 and $4200 \mathrm{~m}$ on the Tibetan Plateau at $29^{\circ} \mathrm{N}$ (Bai et al., 2011), the

155 altitudinal isotope effect has not yet been broadly established in living vegetation.

156 Most prior plant-based calibration efforts have employed small numbers of dominant species

157 (Sachse et al., 2006; Tipple and Pagani, 2013). Such studies have demonstrated the expression of 158 the leaf wax proxy in individual species and have revealed differences between species (Kahmen 159 et al., 2013b). In the tropics, in montane regions and across many strong climatic gradients, plant 160 community turnover, i.e. beta diversity (Condit et al., 2002), presents situations where it is

161 impossible to follow a single species over the distances required to track gradients in the isotopic 162 composition of precipitation. We suggest that tropical species-richness (alpha diversity) and 
turnover (beta diversity) should not be seen as obstacle to effective calibration, but rather we embrace the complexity of these ecosystems as directly of interest, and we aim to collect large, community-representative samples.

\subsection{Andes-Amazon tropical forest hydrogen isotope calibration}

167 In order to advance the use of the plant wax hydrogen isotope proxy for reconstruction of past 168 variations in tropical climates, we conduct a large-scale calibration study in one of the major 169 tropical forests of the world today, including the western Amazonian lowland rainforests and the 170 upland forests of the Peruvian Andes. This transect provides a large precipitation isotopic range $171(>60 \%)$ for effective calibration. We sample plant leaf waxes, leaf water, stem water and

172 precipitation to directly determine hydrogen isotopic fractionations, using a paired

173 ecohydrological and organic geochemical approach previously used to characterize hydrogen

174 isotope systematics in dry, subtropical southern California (Feakins and Sessions, 2010).

175 We incorporate dual hydrogen and oxygen isotope analysis of environmental waters and plant

176 waters to resolve water sources and to constrain whether plants are accessing water on the local

177 meteoric water line (LMWL); to test for the use of waters that are evaporatively-enriched

178 (deemed unlikely in this very wet climate) and to test for the (likely) use of cloud water sources 179 in TMCF ecosystems (Goldsmith et al., 2013), as can be observed from D-excess above the 180 LMWL (Clark et al., 2014).

181 In order to characterize highly biodiverse tropical ecosystems, we sample a large number of 182 individuals and account for community-representation in order to determine the hydrogen 183 isotopic biogeochemical fractionations and compositions relevant at the ecosystem- and 184 landscape-scale. Our approach weights for the waxiness of leaves and the relative abundance of 
185 tree species in order to link between leaf-level calibration sampling and landscape-level

186 sedimentary application. We hypothesize that leaf wax traits will on average record the hydrogen

187 isotopic composition of precipitation. At the individual level we expect isotopic variability in

188 plant water sourcing and biological fractionations based on plant physiological and biochemical

189 differences.

190 By sampling across species, forest plots and elevation, we seek data to support the use of leaf

191 wax biomarkers as a paleohydrological proxy in tropical forests. Specifically, we seek to

192 determine whether ecosystem-scale sampling of living plants' leaf wax biomarkers record local

193 meteoric water isotopic composition in tropical forest ecosystems. We conclude with

194 recommendations for further calibration and application of these plant leaf wax biomarker

195 hydrogen isotopic approaches to reconstruct paleoenvironments. 


\section{MATERIALS AND METHODS}

198 This study included 5 plots (Table 1) that belong to a group of permanent 1-ha plots operated by 199 the Andes Biodiversity Ecosystems Research Group (ABERG,

200 http://www.andesconservation.org) and that are part of the ForestPlots

201 (https://www.forestplots.net/) and Global Ecosystems Monitoring (GEM;

202 http://gem.tropicalforests.ox.ac.uk/projects/aberg) networks.

203 Three montane plots are located in the Kosñipata Valley in the province of Paucartambo, 204 department of Cusco, Peru, and two lowland plots are located in Tambopata in the department of 205 Madre de Dios, Peru (Malhi et al. 2010). All plots are located in areas that have relatively 206 homogeneous soil substrates and stand structure and minimal evidence of human disturbance 207 (Girardin et al., 2014b). The lowland plots were established in the early 1980s, and the montane 208 ones between 2003 and 2013, with all stems $\geq 10 \mathrm{~cm}$ diameter at breast height tagged and 209 identified to species-level. Plots have been annually measured for carbon allocation and cycling 210 following the standard GEM Network protocol (Marthews et al. 2014). As such, net primary 211 productivity estimates (Girardin et al., 2010) and comprehensive descriptions of the carbon cycle 212 exist for all of these plots (Girardin et al., 2014a; Huacara Huasco et al., 2014; Malhi et al., 213 2014a; Malhi et al., 2015).

214 The field-plots are located across the Andes-Amazon elevation gradient, including upper TMCF, 215 lower TMCF and lowland rainforest (Table 1; Fig. 1). Mean annual temperature (MAT) declines 216 with increasing elevation from 24.4 to $13.1^{\circ} \mathrm{C}$. Mean annual precipitation (MAP) increases from $2171900 \mathrm{~mm} \mathrm{yr}^{-1}$ in the lowlands to $5302 \mathrm{~mm} \mathrm{yr}^{-1}$ in the lower TMCF close to the cloud base and 
218 then declines again to $1560 \mathrm{~mm} \mathrm{yr}^{-1}$ in the upper TMCF (Girardin et al., 2014a; Huacara Huasco 219 et al., 2014; Malhi et al., 2014a; Rapp and Silman, 2012). There is a distinct seasonality in the 220 amount of precipitation with $200-800 \mathrm{~mm} \mathrm{month}^{-1}$ precipitation occurring during the November-

221 March wet season and 100 mm month ${ }^{-1}$ in the June-August dry season (Girardin et al., 2014a;

222 Rapp and Silman, 2012). In the montane forest plots, cloud immersion is most common in the 223 dry season (April-September).

\subsection{Meteoric water sampling}

225 Integrated measures of precipitation isotopes were collected every $\sim 2$ weeks for one year using 226 samplers containing mineral oil. The stable $\mathrm{H}$ and $\mathrm{O}$ isotopic composition of precipitation was 227 measured by laser spectroscopy. $\delta \mathrm{D}$ and $\delta^{18} \mathrm{O}$ values were measured simultaneously on 8 228 replicate injections of $0.7 \mathrm{uL}$ water using a Los Gatos Research DLT-1000 liquid water isotope 229 analyzer at the California Institute of Technology. Hydrogen and oxygen isotope ratios (as D:H 230 and ${ }^{18} \mathrm{O}:{ }^{16} \mathrm{O}$ respectively) are expressed in delta notation as 'per mil' or parts per thousand (\%o)

231 relative to the Vienna Standard Mean Ocean Water (VSMOW)-Standard Light Antarctic

232 Precipitation (SLAP) isotopic scale with accuracy determined to better than $0.2 \%$ and

$2330.1 \%$, respectively. Replicate measurements yielded a mean precision $(\sigma)$ of $0.5 \%$ for $\delta \mathrm{D}$ and $2340.2 \%$ for $\delta^{18} \mathrm{O}(n=43)$ and were calibrated using 3 working standards (Maui Water, $\delta \mathrm{D}=$ $235-10.6 \%$, $\delta^{18} \mathrm{O}=-3.3 \%$, Caltech internal standard, $\delta \mathrm{D}=-73.4 \%$, $\delta^{18} \mathrm{O}=-9.7 \%$; and LGR 236 Water $\# 2, \delta \mathrm{D}=-117.0 \%$ o $\delta^{18} \mathrm{O}=-15.5 \%$ ).

237 To capture the representative composition of time-averaged meteoric water across the elevation 238 gradient, we sampled small upland streams and lowland tributaries, each of which were selected 239 for their restricted elevation range catchments. In this way these samples represent the local 
240 water composition at the sampling site. We do not consider river water isotopic composition

241 from the main stem or large tributaries which transport water from higher elevations to the

242 sampling location. Our stream water samples were measured with the same methods described

243 above for precipitation samples and the results were previously reported for hydrogen isotopes

244 (Ponton et al., 2014). Here we re-evaluate these data for their dual isotopic composition and

245 compare to our biweekly precipitation isotope collections described above, as well as prior

246 collections of precipitation and cloud water (Clark et al., 2014; Horwath, 2011) in order to

247 understand meteoric waters across the transect.

249 From April - November 2013 (dry season), we measured plant traits as part of the CHAMBASA

250 (CHallenging Attempt to Measure Biotic Attributes along the Slopes of the Andes) project.

251 Based on the most recently available census and diameter data, a sampling protocol was adopted

252 wherein species were sampled that maximally contributed to plot basal area (a proxy for plot

253 biomass or crown area). At each site at least five species were sampled for plant water and wax

254 analysis. Within each species, three individual trees were chosen for sampling. Using advanced

255 tree climbing techniques, we sampled one fully, sunlit canopy branch and, where it existed, a

256 fully shaded branch, each at least $1 \mathrm{~cm}$ diameter, from each tree. Stems were fully bark-covered

257 (not green). From each branch, we measured 1 to 2 leaves. Branches and leaves were chosen

258 with minimal evidence of damage (i.e. herbivory). Xylem and leaf samples were placed in

259 coolers for transport back to the lab, and were frozen before and after shipping before cryogenic

260 extraction. For plant water and wax hydrogen isotopic analyses, 176 individuals were sampled

261 across 32 species and five forest plots across the Andean-Amazon gradient. 


\subsection{Plant water sampling}

263 Leaf samples were collected in the early afternoon for water extractions and leaf wax analysis as

264 described above by the CHAMBASA protocols. Leaves were cut at the base of the leaf, placed

265 into glass vials and kept cool until analysis. Stem samples were also collected $30 \mathrm{~cm}$ below the

266 leaf and similarly placed into glass vials for xylem water isotopic analyses.

267 Water was cryogenically extracted from the xylem and leaf samples (as described in Vendramini 268 and Sternberg, 2007) for water isotopic analysis. After water extraction, the same leaf tissue was 269 chopped and extracted for leaf wax isotopic composition reported here. Plant waters were 270 analyzed by isotope ratio mass spectrometry (IRMS; Finnigan Mat DeltaPlus XL, Germany) at 271 the UC Berkeley Center for Stable Isotope Biogeochemistry. The stable H isotope composition 272 of all water samples was determined using the method outlined by Nelson and Dettman (2001); 273 the stable $\mathrm{O}$ isotope composition was determined using a 5-day equilibration of water samples 274 with $\mathrm{CO}_{2}$ followed by mass spectrometry analysis (Epstein and Mayeda 1953; Brooks and 275 Dawson 2001). The external precision is better than $0.1 \%$ for $\delta^{18} \mathrm{O}$ and $0.8 \%$ or $\delta \mathrm{D}$.

\subsection{Lipid extraction}

277 Dried, chopped plant leaves were immersed in dichloromethane (DCM):methanol (MeOH; 9:1

$278 \mathrm{v} / \mathrm{v}$ ) and agitated manually by pipette to extract plant waxes in solution. The extract was

279 separated using column chromatography ( $5 \mathrm{~cm} \mathrm{x} 40 \mathrm{~mm}$ Pasteur pipette, $\mathrm{NH}_{2}$ sepra bulk

280 packing, $60 \AA$ ) , eluting with 2:1 DCM:isopropanol, followed by $4 \% \mathrm{HCO}_{2} \mathrm{H}$ in diethyl ether,

281 yielding neutral and acid fractions respectively. The neutral fraction was separated by column 282 chromatography (5 cm x $40 \mathrm{~mm}$ Pasteur pipette, 5\% water-deactivated silica gel, 100-200 mesh) 
283 by eluting with hexanes to separate $n$-alkanes. The acid fraction containing $n$-alkanoic acids was 284 transesterified with $5 \% \mathrm{HCl}$ and $95 \% \mathrm{MeOH}\left(\delta \mathrm{D}_{\text {methanol }}=-198.3 \% \pm 3.9 ; \sigma\right)$ at $70{ }^{\circ} \mathrm{C}$ for 12 285 hours to yield corresponding fatty acid methyl esters (FAMEs). Excess milliQ water was added 286 to the hydrolyzed products, and the lipids were partitioned into hexane and dried by passing 287 through anhydrous $\mathrm{Na}_{2} \mathrm{SO}_{4}$. Lipids were further purified using column chromatography $(5 \mathrm{~cm} \mathrm{x}$ $28840 \mathrm{~mm}$ Pasteur pipette, 5\% water-deactivated silica gel, 100-200 mesh), eluting with hexane first 289 and then with DCM to isolate the pure FAME fraction.

\subsection{Biomarker identification and quantification}

291 We identified the $n$-alkanes and $n$-alkanoic acids (the latter as methyl esters) by gas

292 chromatography mass spectrometry and quantified these compounds by a flame ionization 293 detector relative to an in-house mixture of $n$-alkanes and $n$-alkanoic acid methyl esters of known 294 concentration.

\subsection{Compound-specific hydrogen isotopic analysis}

296 Compound-specific hydrogen isotopic values were obtained using gas chromatography isotope 297 ratio mass spectrometry (GC-IRMS). We used a Thermo Scientific Trace gas chromatograph 298 equipped with a Rxi-5ms column ( $30 \mathrm{~m}$ x $0.25 \mathrm{~mm}$, film thickness $1 \mu \mathrm{m})$ and a programmable 299 temperature vaporizing (PTV) injector operated in solvent split mode with an evaporation 300 temperature of $150{ }^{\circ} \mathrm{C}$ to exclude abundant $\mathrm{C}_{16}$ and $\mathrm{C}_{18} n$-alkanoic acids, following Feakins et al. 301 [2014]. The GC was connected via a GC Isolink with pyrolysis furnace (at $1400{ }^{\circ} \mathrm{C}$ ) via a Conflo

302 IV interface to a DeltaVPlus isotope ratio mass spectrometer. To check for linearity, the $\mathrm{H}_{3}$

303 factor was measured daily and remained close to $4 \mathrm{ppm} \mathrm{mV}^{-1}$ (across 1-8 V). Reference peaks of 
$304 \mathrm{H}_{2}$ were co-injected during the course of a GC-IRMS run; two were used for standardization.

305 Samples were interspersed with standard compound mixtures of known isotopic composition.

306 Data were normalized to the VSMOW/SLAP hydrogen isotopic scale by comparing with an

307 external standard obtained from A. Schimmelmann, Indiana University, Bloomington, containing

$30815 n$-alkane compounds $\left(\mathrm{C}_{16}\right.$ to $\left.\mathrm{C}_{30}\right)$, with $\delta \mathrm{D}$ values spanning -9 to $-254 \%$. The RMS error

309 determined by replicate measurements of the standard across the course of analyses was $4.2 \%$.

310 Correction for $\mathrm{H}$ added by methylation of FAs as methyl esters was made by way of mass

311 balance. The results are reported using conventional delta notation $(\delta \mathrm{D} \%)$.

\subsection{Isotopic fractionations}

313 We compare the measured isotopic values of environmental waters, plant waters and biomarkers

314 in order to calculate the enrichment factors associated with the various isotopic effects. We

315 report isotopic fractionations between two measured substrates, $\delta \mathrm{D}_{\mathrm{a}}$ and $\delta \mathrm{D}_{\mathrm{b}}$, as enrichment

316 factors $\left(\varepsilon_{\mathrm{a} / \mathrm{b}}\right)$, calculated with the following equation:

$317 \quad \varepsilon_{\mathrm{a} / \mathrm{b}}=\alpha_{\mathrm{a} / \mathrm{b}}-1=\left[\left(\delta \mathrm{D}_{\mathrm{a}}+1\right) /\left(\delta \mathrm{D}_{\mathrm{b}}+1\right)\right]-1$

318 where a is the product and $\mathrm{b}$ is the substrate. $\delta \mathrm{D}$ and $\varepsilon$ are reported here in per mil units (\%o)

319 which implies a factor of 1000 (Cohen et al., 2007). When reporting plant water isotopic

320 fractionations, the superscript specifies the enrichment of the heavier isotope of hydrogen

$321\left({ }^{2} \varepsilon_{\mathrm{LW} / \mathrm{XW}}\right)$ or oxygen $\left({ }^{18} \varepsilon_{\mathrm{a} / \mathrm{b} \mathrm{LW} / \mathrm{XW}}\right)$.

\subsection{Community-weighted averaging of plant wax isotopic traits}

323 Since waxiness of plant leaves varies, we weighted the isotopic composition for the

324 concentration of each compound (concentration-weighted plot mean). To account for the variable 
325 contributions of species in a forest plot, we weighted for both wax concentration and abundance

326 of each sampled species (community-weighted plot mean). Species proportional contributions

327 were based on total basal area for each species and taxonomic inventories collected between

3282009 and 2014, during which time there was no major disturbance (e.g. landslide, fire,

329 deforestation) in these old growth forests. The weighted means and the weighted standard

330 deviations were calculated using the general formula:

$331 \quad x w=i=1 N w i \cdot x i i=1 N w i \quad$ (2)

$332 \sigma w=i=1 N w i \cdot(x i-x w) 2\left(N^{\prime}-1\right) \cdot i=1 N w i N^{\prime}$

333 where $\mathrm{w}_{\mathrm{i}}$ is the weight for the $\mathrm{i}^{\text {th }}$ observation, $\mathrm{N}$ is the number of non-zero weights, and $x w$ is the

334 weighted mean of the observations.

335 3. RESULTS

$336 \quad$ 3.1. Meteoric water isotopic composition

337 Biweekly precipitation samples from 4 sites across the elevation profile spanned 9/2/2013 to

$3387 / 23 / 2014$. No samples were collected during the wet season at the high elevations, when heavy

339 rain and landslides make access challenging. Dual isotopic analysis indicates a local meteoric

340 water line (LMWL) of $\delta \mathrm{D}(\%)=7.62 \delta^{18} \mathrm{O}+4.30\left(\mathrm{R}^{2}=0.97 ; n=45\right) ;($ Fig. $2 \mathrm{~A})$. The LMWL

341 from our biweekly sampling is similar to that reported for discrete precipitation samples in prior

342 years from the Andean sector (Clark et al., 2014), as well as to the global meteoric water line

$343(\mathrm{GMWL})$ relationship of $\delta \mathrm{D}(\%)=8 \delta^{18} \mathrm{O}+10(\mathrm{Craig}, 1961)$. Deuterium excess, calculated as $\mathrm{d}$

$344=\delta \mathrm{D}-8 * \delta^{18} \mathrm{O}$, has a mean value of $7 \%$ o $(\sigma=6)$ from the biweekly samples. Biweekly

345 precipitation samples displayed seasonality: $\delta \mathrm{D}$ values ranged over $100 \%$ at each elevation 
346 where year round collections were made (Appendix A). As sampling was not optimized for

347 collecting precipitation amounts, and we do not have wet season sampling from the high

348 elevation sites, we do not attempt to calculate mean annual precipitation isotopic compositions or

349 regression with elevation.

350 Stream water $\delta \mathrm{D}$ values were reported in a prior publication (Ponton et al., 2014), which found

351 the expected depletion of the heavier isotope with elevation with ordinary least squares

352 regression of elevation against $\delta \mathrm{D}$ yielding a slope of $-22 \% \mathrm{~km}^{-1}\left(\mathrm{R}^{2}=0.96, n=24\right.$, dry season)

353 and $-17 \% \mathrm{~km}^{-1}\left(\mathrm{R}^{2}=0.92, n=15\right.$, wet season $)$. Those stream water data are also here

354 considered for their dual isotopic composition. We find stream waters fall within the error of the

355 LMWL (stream $\delta \mathrm{D} \%=8 \delta^{18} \mathrm{O}+15$; shown separated by season of collection in Fig. 2A). The

356 slopes of the isotope-elevation relationship for $\delta^{18} \mathrm{O}$ are $-2.75 \% \mathrm{~km}^{-1}\left(\mathrm{R}^{2}=0.94, n=24\right.$, dry

357 season) and $-1.96 \% \mathrm{~km}^{-1}$ respectively $\left(\mathrm{R}^{2}=0.92, n=15\right.$, wet season). Stream water isotopic

358 composition is identical in wet and dry seasons in the uplands, reflecting the residence time of

359 baseflow from soils and fractured rock (Clark et al., 2014), whereas lowland streams vary

360 seasonally by c. $20 \%$ in $\delta \mathrm{D}$ reflecting a buffered version of the seasonal cycle in the measured

361 isotopic composition of precipitation. We thus find that stream waters average out short-term

362 variability in precipitation, fall on the LMWL and show expected depletion in the heavier

363 isotopes with elevation (Fig. 2A). The stream waters thus substantiate the precipitation sampling,

364 providing a practical means to establish the meteoric water isotopic composition available to

365 plants during brief fieldwork visits to remote settings.

\section{$366 \quad 3.2$. Plant xylem water isotopic compositions}


367 We find a -18 to $-186 \%$ range in the hydrogen isotopic composition of plant xylem waters

$368\left(\delta \mathrm{D}_{\mathrm{Xw}}\right)$ and -3 to $-30 \%$ range in oxygen isotopes $\left(\delta^{18} \mathrm{OXw}\right)$. The slope of the regression of $\delta \mathrm{D}_{\mathrm{Xw}}$

369 and $\delta^{18} \mathrm{O}_{\mathrm{Xw}}$ with elevation is $-21 \% \mathrm{~km}^{-1}\left(\mathrm{R}^{2}=0.85, n=156\right)$ and $-3.90 \% \mathrm{~km}^{-1}$ respectively $\left(\mathrm{R}^{2}\right.$

$370=0.63, n=117)$. Scatter between samples is likely due to temporal and spatial variability in plant

371 water uptake between individuals and species. Xylem waters generally fall near the LMWL, with

372 some notably above the LMWL at ESP-01 (Fig. 2). These xylem water values above the LMWL

373 are indicative of atmospheric vapor sources, and are in part consistent with the range of values

374 for cloud water reported by a prior study (Clark et al., 2014; Horwath, 2011). Those cloud water

375 values are shown on Fig. 2, representing sampling from $\sim 5$ collections at 5 elevations between

$376 \quad 1500$ and 3600 masl during the dry season only. We would expect more depleted precipitation

377 and cloud water at times and this may explain the observed stem water values. Few xylem water

378 values fall below the LMWL, indicating evaporatively-enriched soil water is not a factor here.

\subsection{Leaf water isotopic composition}

380 In three sites, ESP-01, TAM-05 and TAM-06, leaf waters are D-enriched above xylem water 381 (Fig. 3) and dual isotopic analysis reveals that they fall below the LMWL, indicating leaf water 382 evaporative enrichment (Fig. 2B). However, at SPD-01 and SPD-02, leaf waters and xylem 383 waters are indistinguishable or more D-depleted than xylem waters and fall on the LMWL.

384 Using Eqn. 1, we calculate the 'leaf water enrichment,' i.e., the enrichment of bulk leaf water 385 (LW) over xylem water (XW) for both hydrogen $\left({ }^{2} \varepsilon_{\mathrm{LW} / \mathrm{XW}}\right)$ and oxygen $\left({ }^{18} \varepsilon_{\mathrm{LW} / \mathrm{XW}}\right)$. Leaf water 386 enrichment averages $15 \%$ o $(\sigma=22, n=72)$ and $5.9 \%$ o $(\sigma=5.9, n=52)$ for $^{2} \varepsilon_{\mathrm{LW} / \mathrm{XW}}$ and ${ }^{18} \varepsilon_{\mathrm{LW} / \mathrm{XW}}$ 387 respectively across the entire transect. In the lowland tropical forest sites in this study, measured

$388{ }^{2} \varepsilon_{\mathrm{LW} / \mathrm{XW}}$ is small, with a mean value of $+6 \%$ o $(\sigma=6, n=52)$, and negligible at the wettest SPD- 
38901 and SPD-02 sites at c. $1.5 \mathrm{~km}$ asl and highest at the upper site $+29 \%$ o $(\sigma=25, n=18)$. This

390 points to MAP and $\mathrm{RH}$ as the dominant variable in determining $\varepsilon_{\mathrm{LW} / \mathrm{XW}}$ across the elevation

391 profile, consistent with global patterns (Sachse et al., 2012). We find no significant difference

392 between sun and shade leaves overall, indicating that other environmental or plant physiological

393 factors are more important for leaf water enrichment than sun exposure.

\subsection{Leaf wax molecular concentrations}

395 We report the compound-specific concentration of the $n$-alkane and $n$-alkanoic acid homologues

396 for each individual plant sample (Appendix A). n-Alkanes are generally more concentrated than

$397 n$-alkanoic acids. The $\mathrm{C}_{29} n$-alkane has the highest concentration with a mean abundance of 113

$398 \mu \mathrm{g} \mathrm{g}^{-1}$ whereas the $\mathrm{C}_{30} n$-alkanoic acid has a mean of $34 \mu \mathrm{g} \mathrm{g}^{-1}$. Concentrations range over an 399 order of magnitude and in some individuals $n$-alkanoic acid concentrations are too low for 400 isotopic determination.

\subsection{Leaf wax hydrogen isotopic compositions}

402 We measured compound-specific $\delta \mathrm{D}_{\text {wax }}$ values for a total of 176 plant samples from 32 different 403 species and found $\delta \mathrm{D}_{\text {wax }}$ values that range from -102 to $-278 \%$ across all measured compound 404 classes, species and sites (Appendix A). Linear regression of the $\delta \mathrm{D}$ values for $\mathrm{C}_{24}$ to $\mathrm{C}_{32} n^{n}$

405 alkanoic acids and $\mathrm{C}_{27}$ to $\mathrm{C}_{31} n$-alkanes indicate strong relationships between all compounds $\left(\mathrm{R}^{2}\right.$ $406>0.9$ ), with the exception of the $C_{32} n$-alkanoic acid that is restricted to the lower elevation sites.

407 We find the $\delta \mathrm{D}$ values of $n$-alkanoic acids and $n$-alkanes correlate well with xylem water (Fig.

$4084 a, b)$. There is no significant correlation with bulk leaf waters (Fig. 4c, d), which fall in two 
409 clusters, with enriched waters at the lowland (TAM-05 and TAM-06) and upland (ESP-01) sites

410 and non-enriched waters at the wettest sites (SPD-01 and SPD-02).

411 Using Eqn. 1 we calculate the apparent fractionation between $\delta \mathrm{D}$ values of source water and

412 wax. We consider both (1) site mean estimates of source water based on the plot elevation and

413 the ordinary least squares regression-based estimate of stream water measured values for that

414 elevation (w), as well as (2) the directly measured xylem water from individual plants. Since

$415 \delta \mathrm{D}_{\mathrm{XW}}$ is similar to $\delta \mathrm{D}_{\mathrm{w}}$ we also find that the unweighted mean fractionations for these

416 individuals using stream water or xylem waters are the same within uncertainties: $\varepsilon_{28 \mathrm{acid} / \mathrm{w}}=-121$

$417 \pm 31 \%$ o $(\sigma, n=102)$ versus $\varepsilon_{28 \mathrm{acid} / \mathrm{XW}}=-128 \pm 31 \%$ o $(\sigma, n=83)$ and $\varepsilon_{29 / \mathrm{w}}=-129 \pm 22 \%$ o $(\sigma, n=$

$418136)$ versus $\varepsilon_{29 / \mathrm{XW}}=-136 \pm 21 \%\left(\sigma, n=111\right.$; with smaller sample sizes for $\varepsilon_{\mathrm{wax} / \mathrm{XW}}$ due to loss

419 of some xylem water samples). We further find no significant difference in apparent

420 fractionation between sun and shade leaves by Student's t test, indicating that source water (w)

421 and other environmental or plant physiological factors are more important than sun exposure. 


\section{DISCUSSION}

\subsection{Ecohydrology and implications for plant wax $\delta D$}

424 Only a few studies have compared $\delta \mathrm{D}$ values of plant waters with those of plant biomarker

425 molecules across natural environmental transects (e.g., Feakins and Sessions, 2010; Kahmen et

426 al., 2013b; Tipple and Pagani, 2013), and none have done so in a very wet tropical ecosystem. In

427 this study, we add dual isotope analyses of plant waters to add further insights into resolving

428 water sources. We directly sampled xylem waters to establish plant water sources and find that

429 most xylem waters fall on the LMWL with minimal deviations (Fig. 2), indicating precipitation

430 as the major source of water. Some xylem waters fall above the LMWL at the highest TMCF site

431 (ESP-01). These xylem water values may be indicative of atmospheric vapor sources and are in

432 part consistent with the range of values for cloud water and shown on Fig. 2, representing

433 sampling from $\sim 5$ collections at 5 elevations between 1500 and 3600 masl during the dry season

434 only (Clark et al., 2014; Horwath, 2011). We would expect more depleted precipitation and

435 cloud water at times (extrapolating the sampled range) and this may in part explain the few stem

436 water values that fall beyond the available cloud water dataset. As persistent cloud reaching

437 ground level immerses the area (Halladay et al., 2012), we infer that plants are accessing fog

438 inputs to soils, a phenomenon previously documented in TMCF (Eller et al., 2013).

439 We can also establish whether plant source waters are well characterized by the isotopic

440 composition of mean annual precipitation or whether they vary among precipitation events. We

441 find that xylem waters have much less scatter than 2-week integrated precipitation collections

442 that range in $\delta \mathrm{D}$ values by over $\sim 100 \%$ at each site. Instead xylem water isotopic compositions

443 fall close to that of stream water. Stream water is composed of annually-integrated precipitation 
444 stored in soil and fractured rock in the Andes (Clark et al., 2014) and seasonally-integrated

445 meteoric water in the lowland rainforest (Ponton et al., 2014). We infer that xylem water is

446 relatively insensitive to shorter-term variations in precipitation isotopic composition, and that

447 plants are generally accessing water stored in soil and fractured rock.

448 Overall we find a minor enrichment of leaf water above xylem water. ${ }^{2} \varepsilon_{\mathrm{LW} / \mathrm{XW}}$ averages $+15 \pm 2$

$449 \%$ (s.e.m., $n=72$ ) confirming leaf water model projections for the tropics (Kahmen et al., 2013a;

450 West et al., 2008). The suppression of leaf water enrichment results from equilibration of leaf

451 water with atmospheric water vapor at high $\mathrm{RH}$ via exchange through the stomata (Farquhar et

452 al., 2007) and in the TMCF via foliar uptake of precipitation accumulated on leaf surfaces (Eller

453 et al., 2013; Goldsmith et al., 2013) (illustrated in Fig. 5). However, the weak correlation

454 between $\delta \mathrm{D}_{\mathrm{LW}}$ and $\delta \mathrm{D}_{\text {wax }}$ (Fig. $4 \mathrm{c}, \mathrm{d}$ ) leads us to infer that the bulk leaf water, as sampled in the

455 afternoon in the dry season (May-October), is not representative of the substrate for biosynthesis

456 of the lipids. Therefore, we suggest caution in interpreting $\varepsilon_{\mathrm{wax} / \mathrm{LW}}$, the fractionation between

$457 \delta \mathrm{D}_{\mathrm{wax}}$ and bulk leaf water as calculated from this study, as we have likely not captured the

458 fractionation relevant to determining $\varepsilon_{\text {bio. }}$. Leaf water varies in isotopic composition on a diurnal

459 and seasonal basis ( $\mathrm{Li}$ et al., 2006), and spatially within the leaf from the xylem water supply to

460 the enriched water near stomata. Leaf water and leaf waxes were sampled at the same time, but

461 the waxes would have been synthesized from leaf waters at an earlier time, likely soon after leaf

462 formation (Tipple et al., 2013). In the tropics, leaves are formed year round with a slight increase

463 in September during the dry season (Malhi et al., 2014a). Given spatiotemporal variation in leaf

464 water isotopic composition, measured bulk leaf water may not relate to the substrate used for

465 synthesis of leaf waxes. For the purpose of understanding the physical controls on the $\delta \mathrm{D}$ of 
466 plant leaf waxes, we therefore rely upon the $\delta \mathrm{D}_{\mathrm{Xw}}$ (xylem water, Fig. $4 \mathrm{a}, \mathrm{b}$ ) or the $\delta \mathrm{D}_{\mathrm{w}}$ (i.e.

467 stream water as an integrated measure of precipitation). The main water fluxes are schematically

468 illustrated as relevant for leaf wax hydrogen isotope systematics in Fig. 5.

\subsection{The fractionations between meteoric waters and plant leaf waxes}

470 The net or apparent fractionation $\left(\varepsilon_{\mathrm{app}}\right)$ between water and wax is the most commonly reported

471 fractionation (Fig. 5), where water is typically mean annual precipitation isotopic composition,

472 often derived from interpolations of sparse observational data. In order to establish whether leaf

473 wax biomarkers record local meteoric water isotopic composition, we measured plant water and

474 wax isotopic composition and directly determined fractionations at the individual tree level.

475 Overall, we find $\varepsilon_{\mathrm{wax} / \mathrm{w}}$ (i.e. here measured directly between source water and leaf wax) for $\mathrm{C}_{28} n$ -

476 alkanoic acids to be $-121 \pm 3 \%$ (s.e.m, with $31 \% 0 \sigma, n=102$; Fig. 6 c) and for $\mathrm{C}_{29} n$-alkanes to

477 be $-129 \pm 2 \%$ (s.e.m, with $22 \% 0 \sigma, n=136$; Fig. $6 \mathrm{~d}$ ). In this ecosystem, we find that $\varepsilon_{\mathrm{wax} / \mathrm{w}}$ and

$478 \varepsilon_{\mathrm{wax} / \mathrm{XW}}$ are indistinguishable within uncertainties overall, indicating that the variability of plant

479 waters from stream water values is no larger than variability associated with biosynthesis. The

480 picture of hydrogen isotope systematics that emerges is as follows. In this very wet tropical

481 ecosystem, with $2-5 \mathrm{~m}$ of rainfall per year, precipitation inputs to soil and rock storage average

482 out variability between storms (Clark et al., 2014) and the water that is either stored, exported in

483 small stream flow or accessible to plants is isotopically indistinguishable. This finding confirms

484 the validity of using measured small stream water values in place of plant water sampling or

485 precipitation isotope collections that are hard to maintain in remote regions. Notably, we find

486 that the leaf wax proxy operates along this moist tropical elevation transect with only a 
487 negligible contribution from the leaf water enrichment as predicted in a prior modeling study

488 (Kahmen et al., 2013a).

489 These fractionations are consistent with those reported in humid areas globally (Sachse et al., 490 2012), for example $\varepsilon_{\mathrm{wax} / \mathrm{w}}$ in these tropical forests is no different from those reported for a humid, 491 temperate forest in Massachusetts, USA (Hou et al., 2007). In that temperate forest $\varepsilon_{\mathrm{wax} / \mathrm{w}}$ for the $492 \mathrm{C}_{29} n$-alkane was $-130 \pm 4 \%$ (standard error of the mean, s.e.m., $n=35$ ), calculated relative to 493 interpolated precipitation isotope estimates (Hou et al., 2007), similar to the value we found for 494 this Peruvian tropical forest $(-129 \pm 2 \%$ s.e.m., $n=136)$ relative to measured environmental 495 waters. Given the difference in sample size and different or unknown sampling strategies, the 496 variance cannot be quantitatively or qualitatively evaluated between the two studies. The key 497 findings are that we do not find that megadiverse tropical rainforests present particular obstacles 498 to leaf wax proxy reconstructions, and we find the same $\varepsilon_{\mathrm{wax} / \mathrm{w}}$ fractionations in both temperate 499 and tropical forests.

500 Within our study we did however find that the range of $\varepsilon_{\mathrm{wax} / \mathrm{w}}$ variability was larger at the 501 Andean sites (SPD-02 and above) than in lowland rainforest sites. The range of fractionations at 502 the individual plant level is interesting, as it includes some surprisingly small fractionations in 503 the very wet tropical montane climatic environment. Fractionations $<-100 \%$ o have previously 504 only been reported from locations with $<2 \mathrm{~m} \mathrm{yr}^{-1}$ precipitation (Sachse et al., 2012), including 505 locations with an order of magnitude less MAP (Feakins and Sessions, 2010) than in our study 506 sites in Peru. Here we find a large number of individuals with $\varepsilon_{\mathrm{wax} / \mathrm{w}}<-100 \%$ (Fig. 6), in very 507 wet climates with $5 \mathrm{~m} \mathrm{yr}^{-1}$ precipitation. We hypothesize that foliar water uptake in the TMCF 508 may sometimes result in smaller than expected $\varepsilon_{\mathrm{wax} / \mathrm{w}}$. Intriguingly, fractionations at SPD-01 are 
smaller than at SPD-02 (especially for the $n$-alkanoic acids); these are two neighboring sites that

510 differ in fog inundation falling above and below the cloud base respectively (Halladay et al.,

511 2012). This pattern would be consistent with foliar uptake of fog waters in cloud forests

512 (Goldsmith et al., 2013; Gotsch et al., 2014), but this hypothesis was not supported by our one-

513 time sampling of leaf water in this study. Instead we found $\delta \mathrm{D}_{\mathrm{LW}}$ lower than $\delta \mathrm{D}_{\mathrm{XW}}$ values (Fig.

514 3), perhaps reflecting a single D-depleted precipitation and foliar uptake event. While we suspect

515 that source water variability in cloud forests may introduce isotope effects, we cannot explain

516 these plant water observations satisfactorily with available data at this time. Diurnal and seasonal

517 plant water sampling (Gotsch et al., 2014) paired with leaf wax analysis, or experimental studies,

518 could document how foliar uptake in the TMCF may introduce isotope effects in plant leaf

519 waxes, in order to determine the physiological or biochemical basis of the small fractionations

520 observed in a few species. Overall, these species appear to be outliers and we do not find a

521 significant difference in the central estimate of fractionations for upland tropical forests

522 compared to that of lowland tropical forests in this study, or from those of temperate forests.

\subsection{Comparison of $\boldsymbol{n}$-alkanes and $\boldsymbol{n}$-alkanoic acids}

524 Both $n$-alkanes and $n$-alkanoic acids are commonly employed in leaf wax biomarker studies;

525 however, few calibration studies have provided data for multiple compound classes. From 176

526 plant samples that include 32 different species in our Peruvian tropical forest transect, comparing

527 compound classes, we found similar regressions of $\delta \mathrm{D}_{\text {wax }}$ as a function of elevation (Fig. 3), and

528 similar relationships of $\delta \mathrm{D}_{\text {wax }}$ as a function of xylem water across all chain lengths (Fig. 4a, b).

529 Our new results augment data from temperate sites in Japan (Chikaraishi and Naraoka, 2007) and 530 from Massachusetts, USA (Hou et al., 2007); both those prior studies indicated that $n$-alkanes 
531 were depleted by up to $30 \%$ relative to $n$-alkanoic acids. Long chain alkyl lipids are synthesized

532 from the addition of 2 carbon acid groups to yield long chain $n$-alkyl acyl-ACP of carbon chain

533 length $\mathrm{n}$, forming even chain length $n$-alkanoic acids also of length $\mathrm{n}$, as well as $n$-alkanes of $\mathrm{n}-1$

534 (Chikaraishi and Naraoka, 2007; Zhou et al., 2010). We therefore compare pairs of $\mathrm{C}_{\mathrm{n}} n$-acid and

$535\left(\mathrm{C}_{\mathrm{n}-1}\right) n$-alkane to assess the isotopic fractionation associated with the decarboxylation process

536 and any resulting compound class offset that would be relevant for paleoclimate applications.

537 For some individuals we have $\delta \mathrm{D}_{\text {wax }}$ values for both the $\mathrm{C}_{30} n$-alkanoic acid and the $\mathrm{C}_{29} n$-alkane,

538 and we found a mean D-depletion of the $n$-alkane by $-3 \%$ ( $\sigma=17 \%$ for a sample size of 64

539 individuals from 16 different species). Neither the mean nor median of $\varepsilon_{30 \mathrm{acid} / \mathrm{w}}$ and $\varepsilon_{29 / \mathrm{w}}$

540 fractionations significantly differed by Student's $t$ test. Comparison of other pairs of acid and

541 alkane of chain length (i.e., $\mathrm{n}$ and $\mathrm{n}-1$ pairs) yield similar results. This is in contrast to the two

542 prior studies that found an offset between compound classes and we suggest the difference may

543 perhaps be a function of the small sample sizes in those prior studies. In these tropical trees we

544 found species with compound class offsets on the order of $\pm 30 \%$ as well as individuals and

545 species that showed little offset, leading to the overall compound class offset being insignificant.

546 We speculate that the differences in compound class offsets that we observed in some species

547 may arise due to biosynthetic differences in the production of each compound class between

548 species, such as temporal offsets and use of stored carbohydrates; as the lack of overall,

549 consistent difference does not support prior hypotheses of a large fractionation associated with

550 decarboxylation. We note that in sedimentary records offsets between compound classes may

551 arise for additional reasons such as polarity (affecting aqueous or sedimentary affinity) or

552 lability. 
553 These data would tend to support the use of the $n$-alkanes over the $n$-alkanoic acids as proxy

554 records based on a couple of observations. 1) We observe greater variability in the $n$-alkanoic

555 acid isotopic values than among the $n$-alkanes. For example, site-to-site variability in $\varepsilon_{28 a c i d / w}(\sigma$

$556=40 \%$; Fig. $6 \mathrm{c})$ is double that for $\varepsilon_{29 / \mathrm{w}}(\sigma=19 \%$; Fig. $6 \mathrm{~d}) .2$ ) In addition, $n$-alkanes are more

557 abundant in most sampled individuals (Appendix A). Thus on both counts we infer that $n$ -

558 alkanes may be more robust recorders of precipitation isotope signals in living tropical trees and

559 tropical ecosystems. However we note that $n$-alkanoic acids confer advantages and have been

560 often applied in sedimentary systems (Galy et al., 2011; Ponton et al., 2014), whether because of

561 concerns over petrogenic inputs of $n$-alkanes (Pearson and Eglinton, 2000) or because of higher

562 abundances of $n$-alkanoic acids, perhaps as a result of better packaging and preservation in

563 sediments. Consideration of the utility of compound classes should consider living vegetation

564 (which may favor a focus on $n$-alkanes), as well as sedimentary transformations and application

565 (which may favor a focus on $n$-alkanoic acids). Choice of the target chain length may often

566 practically be constrained by relative abundance, interference on the chromatogram and

567 consideration of sources, however we show here, that in plants themselves, all reported $n$ -

568 alkanoic acid and $n$-alkane chain lengths record the primary $\delta \mathrm{D}_{\mathrm{Xw}}$ signal (Fig. $4 \mathrm{a}, \mathrm{b}$ ).

\subsection{Community-averaged plant wax isotopic compositions}

570 When calculating community-averages we must account for the fact that individual plants vary

571 not only in their compound-specific isotopic composition but also in the amount of individual

572 leaf wax compounds produced. We thus scale isotopic measurements and fractionations by wax

573 concentration at the individual level (Fig. 6a, b, 7a, b), an approach that has been also suggested 
574 in a study of African ecosystems (Garcin et al., 2014) and we report concentration-weighted 575 means for each site (Fig. 6c, d, 7c, d).

576 Species also vary in their dominance within the plant community. We further report the 577 community-weighted mean leaf wax isotopic compositions and fractionations, i.e. a central 578 estimate that accounts for both the different concentration of leaf waxes (on a compound-specific 579 basis) and the relative abundance of each species in the forest plot (based on basal area) yielding 580 the 'community-weighted' mean, our best estimate (Fig. 6c, d, 7c, d). The total proportion of the 581 community represented by our sampling is illustrated on a site-by-site basis (Fig. 6e). Sites with 582 low representation are more likely to have offsets between estimates of the mean with different 583 weighting schemes and are more likely to have biased estimates of the mean based on small 584 sample sizes (e.g., SPD-01). Apparent fractionations can be directly compared across all sites 585 and we find surprising agreement in the central estimates across the transect. We find that the 586 overall mean and $\sigma$ of all individuals encompasses the central values for all sites (Fig. 6c, d); 587 thus we find no significant bias in apparent fractionations along the elevation profile.

588 Given the lack of systematic variation in apparent fractionation, community-weighted mean $589 \delta \mathrm{D}_{\text {wax }}$ responds to elevation with a slope of $-17 \% \mathrm{~km}^{-1}$ for the $n$-alkanoic acids and $-18 \% \mathrm{~km}^{-1}$ 590 for the $n$-alkanes (Fig. 7c, d). These slopes carry error associated with the standard errors of site 591 means, as well as unquantifiable uncertainty associated with the small number of sites, and low 592 proportion of community representation (illustrated on Fig. 6). Thus, the errors on the slopes are 593 poorly constrained but are assumed to be greater than site uncertainties and therefore $>5 \% \mathrm{~km}^{-1}$. 594 The altitude effect in meteoric water, as sampled by stream waters, displays gradients of $-22 \%$ 
$595 \mathrm{~km}^{-1}$ in the dry season and $-17 \% \mathrm{~km}^{-1}$ in the wet season. Within uncertainties, we conclude that

596 the isotope-elevation slopes for wax are equivalent to that of meteoric water.

597 For the $n$-alkanoic acids, the mean value for site SPD-01 appears as an outlier from the linear 598 trend defined by the other 4 sites, as illustrated by comparing this sites inclusion and removal 599 from the dataset (Fig 7c). The proportion of the community represented by our sampling at this 600 site may be insufficient to characterize accurately the site mean value, as this value is based upon 601 only 4 species that comprise just $2 \%$ of total basal area (Appendix A). Our failure to sample 602 adequately at SPD-01, is expected to introduce accuracy errors into our central estimate for this 603 site (Paine et al., 2015) and emphasizes the need for large sample sizes and/or assessments of 604 representation. Overall our sampling yielded leaf wax $\delta \mathrm{D}$ results with sample sizes per hectare 605 plot comprising 11 - 32 samples from $3-8$ species (i.e., fewer than sampled, given low $n$ 606 alkanoic acid concentrations in some samples). The sampled species represent $23-406$ stems 607 (total number of stems of sampled species) and $2-53 \%$ of basal area in each forest plot 608 (Appendix A). We identified the predicted relationship with elevation for the community609 weighted mean $\delta \mathrm{D}$ values of the $n$-alkanes (Fig. 7). Although our sampling may not be sufficient 610 to rule out accuracy errors associated with sample means being biased estimates of population 611 means, the census counts allow us to quantify how representative the samples are and to evaluate 612 appropriate strategies for future work.

613 As our sampling targeted prevalent species, the community-weighted mean estimates for both $614 \varepsilon_{\mathrm{wax} / \mathrm{w}}$ (Fig. 6) and leaf wax $\delta \mathrm{D}$ (Fig. 7) are not significantly different from the unweighted 615 sample mean within uncertainties. This may be taken as indication that community-weighting is 616 not necessary, but, we caution that if studies target species without attention to dominance, then 
617 community-weighting may be more critical. In particular, studies that sample across

618 phylogenetic diversity and consequently include species that are either functioning very

619 differently (e.g. water uptake, seasonality of growth) or biosynthesizing differently (e.g. varied

620 use of stored carbohydrates) we would expect isotope effects. For example, rare species

621 occupying distinct niches may have functions that differ from dominant species.

622 In summary, sampling guided by community-representation should be a robust approach to

623 calibration in all ecosystems. In tropical rainforests, collecting large sample sizes and focusing

624 on common species is recommended to understand landscape-scale biogeochemical signatures.

625 Community-weighting may be more important at sites of low diversity and high dominance,

626 such as alpine grasslands (Lavorel et al., 2008), where a few species may exert a strong influence

627 on the central estimate by having a unique water uptake or biosynthesis strategy.

\subsection{General implications for paleoclimate applications}

629 This comprehensive study of hydrogen isotope systematics in tropical lowland and montane

630 rainforests provides modern observational data to support tropical paleoclimate reconstructions.

631 Strong correlations $\left(\mathrm{R}^{2}=0.97\right)$ between $\delta \mathrm{D}_{\mathrm{w}}$ and community-averaged $\delta \mathrm{D}_{\text {wax }}$ values support

632 application of the leaf wax hydrogen isotope proxy for paleoprecipitation (Fig. 8). This study

633 constitutes the first major calibration of hydrogen isotopes systematics - environmental waters,

634 plant waters and plant leaf wax - in tropical forest ecosystems. Model predictions of minimal

635 leaf water isotopic enrichment $(<20 \%)$ in tropical forests including Amazonian forests (Kahmen

636 et al., 2013b) are confirmed here with ${ }^{2} \varepsilon_{\mathrm{LW} / \mathrm{XW}}$ mean enrichment of $+15 \pm 2 \%$ (s.e.m., $n=72$ ).

637 We do not find substantive differences between mean $\varepsilon_{\mathrm{wax} / \mathrm{w}}$ for the $\mathrm{C}_{29} n$-alkanes for these

638 tropical forests $(c .-129 \%)$ and prior data collection in multiple studies for $\mathrm{C}_{3}$ trees $(c .-121 \%)$ 
639 from extratropical locations (Sachse et al., 2012). We also find no significant overall offset

640 between $n$-alkanes and $n$-alkanoic acids, in contrast to prior reports, and therefore combine both

641 compound classes in regression of $\delta \mathrm{D}_{\text {wax }}$ on $\delta \mathrm{D}_{\mathrm{w}}$ (Fig. 8). These calibrations justify using a value

642 of $\varepsilon_{\mathrm{wax} / \mathrm{w}}$ value of $c .-130 \%$ when reconstructing paleoprecipitation $\delta \mathrm{D}$ values in tropical forests,

643 and indeed all moist forest environments. Proxy uncertainties derive from multiple factors, many

644 of which are incompletely quantified, but overall are likely $>10 \%$ and this impacts the precision

645 and accuracy of paleoprecipitation reconstructions. Importantly, we find no $\varepsilon_{\mathrm{wax} / \mathrm{w}}$ change along a

646 fully-forested transect with high alpha and beta diversity, suggesting that tropical reconstructions

647 will also be robust to species turnover so long as ecosystems remain forested over geological

648 time.

649 Based on global calibration efforts across climate systems and ecosystems, the main

650 complications for the leaf wax $\delta$ D proxy arise when a) shifting into dry climates, which entail

651 smaller apparent fractionations of up to $c$. $-90 \%$ due to leaf water enrichment or b) shifting to

652 grassland ecosystems with attendant larger fractionations up to $c$. $-150 \%$ due to leaf physiology

653 (Sachse et al., 2012). Although dry woody, subtropical ecosystems in California were found to

654 exhibit smaller fractionations $c$. $-90 \%$, no sensitivity to the gradient in MAP and RH was

655 detected across that aridity transect, presumably because of varied plant adaptive responses to

656 climate (Feakins and Sessions, 2010). Identifying the transition between wet and dry ecosystems

657 and thus knowing which fractionation to apply is important for paleo-applications. Global

658 compilations indicate that the transition appears to occur around $600 \mathrm{~mm} \mathrm{a}^{-1}$ precipitation and

$659<0.65 \%$ mean relative humidity (Sachse et al., 2012). In order to detect such transitions and to

660 yield paleoprecipitation isotope reconstructions that are robust to these climatic and ecological 
661 changes, applications of the leaf wax proxy would benefit from multi-proxy reconstruction with

662 other moisture proxies, e.g., grain size for runoff or pollen for plant community assemblages

663 (Dingemans et al., 2014), in order to resolve whether a shift in fractionation is likely across the

664 reconstruction period. Such studies would yield both wet-dry and precipitation isotope

665 reconstructions adding value to climate interpretations. In addition, pollen reconstructions of

666 plant types, and in particular grass $\%$, are useful complements to leaf wax $\delta \mathrm{D}$ measurements

667 towards robust paleoprecipitation $\delta \mathrm{D}$ reconstructions (Feakins, 2013).

668 Replication of calibration efforts in other tropical forests, e.g. central Africa and southeast Asia, 669 remains an important test, given the taxonomic differences of tropical forests that may incur 670 hydrogen isotope effects associated with biosynthesis. In those other major tropical forest 671 systems additional forest plot calibration studies would help to secure application of the proxy

672 elsewhere. As part of systematic efforts to specifically assess taxonomic differences (rather than

673 community/landscape averages), phylogenetic sampling schemes may replace forest plot

674 approaches. Phylogenetic studies (Diefendorf et al., 2011; Diefendorf et al., 2015; Gao et al.,

675 2014) have begun to assess systematic genetic bases for plant wax trait variations and

676 fractionation differences. In phylogenetic studies, we recommend sampling with attention to

677 phylogenic position and adequate representation in that case pertains to the number of samples

678 per phylogenetic branch as well as to sampling the full range of environments in which those

679 taxa are found in order to separate environmental effects from taxonomic effects. Whatever the

680 approach to calibration and study of modern ecosystems, there remain limitations in geological

681 application. We must remember that widening the scope of modern calibration cannot fully

682 constrain uncertainties in the past due to plant adaptation and evolution, except in rare cases 
683 where plant leaf waxes as well as other archives of precipitation isotopes co-occur and allow

684 paleo-calibration determinations of leaf wax fractionations (Porter et al., 2016).

685 In terms of additional calibration needs for tropical applications of the leaf wax $\delta \mathrm{D}$ proxy we

686 highlight 3 key areas. 1) Further calibration work extending into seasonally dry tropical forests

687 and mixed savanna ecosystems should be a priority for enabling robust paleoprecipitation isotope

688 reconstructions across wet-dry climate shifts in the tropics. 2) Systematic studies of tropical

689 hydrological processes might include observational or manipulation studies of foliar uptake in

690 cloud forests in order to assess impacts on leaf wax $\delta \mathrm{D}$ values. 3) Additional unanswered

691 questions pertain to tropical seasonality: although temperature seasonality is minimal compared

692 to higher latitude climates, there is light seasonality even in low latitudes, including that

693 associated with cloud cover (Halladay et al., 2012). In this ecosystem, there is a dry season

694 (September) increase in new leaves, although leaf production continues year-round (Malhi et al.,

695 2014a). In temperate zones, a spring bias in leaf growth and wax production indicates the

696 seasonal nature of the temperate forest leaf wax recorder (Tipple et al., 2013). While we find a

697 correlation between $\delta \mathrm{D}$ wax and year-round precipitation isotopes, it remains an open question

698 for timeseries research as to whether tropical leaf waxes are year-round integrators. If there is

699 any seasonal bias, we would predict preferential recording in the dry season, due to light-

700 triggered leaf flush, but we anticipate a more annually-integrative proxy in tropical applications

701 than elsewhere.

\section{5. CONCLUSIONS}

703 We have conducted a multi-species calibration of the leaf wax $\delta \mathrm{D}$ proxy in plant waters and

704 environmental waters across an elevation gradient extending from tropical lowland rainforest to 
montane cloud forest ecosystems. Our survey supports the use of leaf wax biomarkers as

706 paleohydrological proxies in the tropics. In particular, we find that the community-weighted

707 mean wax isotopic compositions primarily record variations in the isotopic compositions of

708 meteoric waters, thus validating the use of leaf wax biomarker hydrogen isotopic compositions to

709 reconstruct paleohydrology in tropical forests. We find that the hydrogen isotopic composition of

710 plant leaf waxes reflects that of precipitation after a larger biosynthetic fractionation as observed

711 globally (Sachse et al., 2012), but that in high relative humidity atmospheres they are less

712 affected than other ecosystems by the secondary isotope effects associated with leaf water

713 enrichment, simplifying the application of this proxy to reconstruct the hydrogen isotopic

714 composition of precipitation in wet tropical climates. We can reject our hypothesized link

715 between high biodiversity and variable fractionations, such as might be expected if species and

716 functional diversity in plant communities entails using differing growth strategies, including

717 differing seasonality or use of stored carbohydrates. Instead we find the lowland rainforest does

718 not display greater isotopic variability than other ecosystems. Furthermore, low dominance in

719 such ecosystems means that no one species exerts a very large effect on ecosystem mean values.

720 Instead, we identify more potential for biased estimates in the TMCF where dominance is higher,

721 and where water sources include both precipitation and fog. Our plot-based transect provides an

722 ecologically- and spatially-representative sampling approach across tropical lowland rainforest

723 and montane cloud forests to characterize landscape-scale plant traits, and offer a window into

724 the living assemblage of leaf wax traits for comparison to the molecular fossils in sediments that

725 represent an archive of past ecosystems and environments.

\section{Acknowledgements}


727 Contributing authors are part of the Andes Biodiversity and Ecosystems Research Group

728 ABERG (andesresearch.org), the Global Ecosystems Monitoring (GEM) network

729 (gem.tropicalforests.ox.ac.uk) and the Amazon Forest Inventory Network RAINFOR

730 (www.rainfor.org) research consortia. The field campaign was funded by grants to YM from the

731 UK Natural Environment Research Council (Grants NE/D01025X/1, NE/D014174/1), with

732 additional support from European Research Council advanced investigator grants GEM-TRAITS

733 (321131) and T-FORCES (291585) as well as the Jackson Foundation to YM and a John D. and

734 Catherine T. MacArthur Foundation grant to GA. GA and the spectranomics team were

735 supported by the endowment of the Carnegie Institution for Science, and by the National Science

736 Foundation (DEB-1146206), supporting the taxonomic contributions to the project. Carnegie

737 Airborne Observatory data collection, processing and analyses were funded solely by the John D.

738 and Catherine T. MacArthur Foundation. The Carnegie Airborne Observatory is supported by the

739 Avatar Alliance Foundation, John D. and Catherine T. MacArthur Foundation, Andrew Mellon

740 Foundation, David and Lucile Packard Foundation, Mary Anne Nyburg Baker and G. Leonard

741 Baker Jr., and William R. Hearst III. Laboratory work at USC was in part supported by the US

742 National Science Foundation (EAR-1227192) and the ACS Petroleum Research Fund (53747-

743 ND2) to SF. We thank the Servicio Nacional de Áreas Naturales Protegidas por el Estado

744 (SERNANP) and personnel of Manu and Tambopata National Parks for logistical assistance and

745 permission to work in the protected areas. We also thank the Explorers' Inn and the Pontifical

746 Catholic University of Peru (PUCP), as well as Amazon Conservation Association for use of the

747 Tambopata and Wayqecha Research Stations, respectively. Many researchers were involved in

748 the field, in particular we would like to thank E. Cosio, W. Huaraca-Huasca and J. Huaman for

749 advising on field logistics; tree climbers: C. Costas, D. Chacón, H. Ninatay; field project 
750 supervision: T. Boza, M. Raurau; species identification and basal area: W. Farfan, F. Sinca; leaf

751 areas R.M. Castro, G. Rayme, A. Robles, Y. Choque and Y. Valdez; and precipitation isotope

752 collections: T. Gonzalez, Amazon Center for Environmental Education and Research in Puerto

753 Maldonado; A. Whitworth, CREES at Manu Learning Center and N. Schulz, PUCP at SP and

754 WAY. We thank USC undergraduate lab assistants: C. Hua, K. McPherson, E. Rosca and A.

755 Figueroa, as well as M. Rincon. This manuscript was improved with the comments of 3

756 anonymous reviewers and Associate Editor Alex Sessions.

757

758

759

760

761

\section{References}

762 Asner, G.P., Llactayo, W., Tupayachi, R., Luna, E.R. (2013) Elevated rates of gold mining in the 763 Amazon revealed through high-resolution monitoring. Proc. Nat. Acad. Sci. U.S.A 110, 18454 76418459.

765 Bai, Y., Fang, X.M., Gleixner, G. and Mugler, I. (2011) Effect of precipitation regime on delta D 766 values of soil $n$-alkanes from elevation gradients - Implications for the study of paleo-elevation. 767 Org. Geochem. 42, 838-845.

768 Bai, Y., Fang, X.M., Jia, G.D., Sun, J.M., Wen, R. and Ye, Y.Q. (2015) Different altitude effect 769 of leaf wax $n$-alkane delta $\mathrm{D}$ values in surface soils along two vapor transport pathways, 770 southeastern Tibetan Plateau. Geochim. Cosmochim. Acta 170, 94-107.

771 Becker, A., Korner, C., Gurung, A.B. and Haeberli, W. (2007) Selected issues from the Samedan 772 GLOCHAMORE workshop on altitudinal gradient studies. Mt. Res. Dev.. 27, 82-86. 
773 Bruijnzeel, L.A., Mulligan, M. and Scatena, F.N. (2011) Hydrometeorology of tropical montane 774 cloud forests: emerging patterns. Hydrol. Process. 25, 465-498.

775 Chikaraishi, Y. and Naraoka, H. (2007) delta C-13 and delta D relationships among three n-alkyl 776 compound classes (n-alkanoic acid, $n$-alkane and $n$-alkanol) of terrestrial higher plants. Org.

777 Geochem. 38, 198-215.

778 Clark, K.E., Torres, M.A., West, A.J., Hilton, R.G., New, M., Horwath, A.B., Fisher, J.B., Rapp, 779 J.M., Robles Caceres, A. and Malhi, Y. (2014) The hydrological regime of a forested tropical 780 Andean catchment. Hydrol. Earth Syst. Sci. 18, 5377-5397.

781 Cohen, E.R., Cvitaš, T., Frey, J.G., Holmström, B., Kuchitsu, K., Marquardt, R., I. Mills, F.P., 782 Quack, M., Stohner, J., Strauss, H.L., Takami, M. and Thor, A.J. (2007) Quantities, Units and 783 Symbols in Physical Chemistry, 3rd. Ed. Royal Society of Chemistry Publishing, Cambridge, 784 UK, pp. 265.

785 Condit, R., Pitman, N., Leigh, E.G., Chave, J., Terborgh, J., Foster, R.B., Nunez, P., Aguilar, S., 786 Valencia, R., Villa, G., Muller-Landau, H.C., Losos, E. and Hubbell, S.P. (2002) Beta-diversity 787 in tropical forest trees. Science 295, 666-669.

788 Cox, P.M., Betts, R.A., Collins, M., Harris, P.P., Huntingford, C. and Jones, C.D. (2004)

789 Amazonian forest dieback under climate-carbon cycle projections for the 21st Century. Theor. 790 Appl. Climatol. 78, 137-156.

791 Craig, H. (1961) Isotopic variations in natural waters. Science 133, 1702-1703.

792 Dawson, T.E. (1998) Fog in the California redwood forest: ecosystem inputs and use by plants. 793 Oecologia 117, 476-485.

794 Diefendorf, A.F., Freeman, K.H., Wing, S.L. and Graham, H.V. (2011) Production of n-alkyl 795 lipids in living plants and implications for the geologic past. Geochim. Cosmochim. Acta $\mathbf{7 5}$, $796 \quad 7472-7485$. 
797 Diefendorf, A.F., Leslie, A.B. and Wing, S.L. (2015) Leaf wax composition and carbon isotopes 798 vary among major conifer groups. Geochim. Cosmochim. Acta 170, 145-156.

799 Dingemans, T., Mensing, S.A., Feakins, S.J., Kirby, M.E. and Zimmerman, S.H. (2014) 3000

800 years of environmental change at Zaca Lake, California, USA. Front. Ecol. Evol. 2, doi: $801 \quad 10.3389 /$ fevo.2014.00034.

802 Eller, C.B., Lima, A.L. and Oliveira, R.S. (2013) Foliar uptake of fog water and transport 803 belowground alleviates drought effects in the cloud forest tree species, Drimys brasiliensis 804 (Winteraceae). New Phytol. 199, 151-162.

805 Ernst, N., Peterse, F., Breitenbach, S.F.M., Syiemlieh, H.J. and Eglinton, T.I. (2013) Biomarkers 806 record environmental changes along an altitudinal transect in the wettest place on Earth. Org. 807 Geochem. 60, 93-99.

808 Farquhar, G.D., Cernusak, L.A. and Barnes, B. (2007) Heavy water fractionation during 809 transpiration. Plant Physiol. 143, 11-18.

810 Feakins, S. and Sessions, A.L. (2010) Controls on the D/H ratios of plant leaf waxes from an arid 811 ecosystem. Geochim. Cosmochim. Acta 74, 2128-2141.

812 Feakins, S.J. (2013) Pollen-corrected leaf wax D/H reconstructions of northeast African 813 hydrological changes during the late Miocene. Palaeogeog. Palaeoclim. Palaeoecol. 374, 62-71.

814 Feakins, S.J., Warny, S. and Lee, J.-E. (2012) Hydrologic cycling over Antarctica during the 815 middle Miocene warming. Nat. Geosci. 5, 557-560.

816 Galy, V., Eglinton, T., France-Lanord, C. and Sylva, S. (2011) The provenance of vegetation and 817 environmental signatures encoded in vascular plant biomarkers carried by the Ganges818 Brahmaputra rivers. Earth Planet. Sci. Lett. 304, 1-12.

819 Gao, L., Edwards, E.J., Zeng, Y. and Huang, Y. (2014) Major Evolutionary Trends in Hydrogen 820 Isotope Fractionation of Vascular Plant Leaf Waxes. Plos One 9, e112610. 
821 Gao, L., Guimond, J., Thomas, E. and Huang, Y.S. (2015) Major trends in leaf wax abundance, 822 delta H-2 and delta C-13 values along leaf venation in five species of C-3 plants: Physiological 823 and geochemical implications. Org. Geochem. 78, 144-152.

824 Garcin, Y., Schefuß, E., Schwab, V.F., Garreta, V., Gleixner, G., Vincens, A., Todou, G., Séné, 825 O., Onana, J.-M., Achoundong, G. and Sachse, D. (2014) Reconstructing C3 and C4 vegetation 826 cover using n-alkane carbon isotope ratios in recent lake sediments from Cameroon, Western 827 Central Africa. Geochim. Cosmochim. Acta 142, 482-500.

828 Girardin, C.A.J., Espejob, J.E.S., Doughty, C.E., Huasco, W.H., Metcalfe, D.B., Durand-Baca, 829 L., Marthews, T.R., Aragao, L., Farfan-Rios, W., Garcia-Cabrera, K., Halladay, K., Fisher, J.B., 830 Galiano-Cabrera, D.F., Huaraca-Quispe, L.P., Alzamora-Taype, I., Eguiluz-Mora, L., Salinas831 Revilla, N., Silman, M.R., Meir, P. and Malhi, Y. (2014a) Productivity and carbon allocation in a 832 tropical montane cloud forest in the Peruvian Andes. Plant Ecol. Divers. 7, 107-123.

833 Girardin, C.A.J., Farfan-Rios, W., Garcia, K., Feeley, K.J., Jorgensen, P.M., Murakami, A.A., 834 Perez, L.C., Seidel, R., Paniagua, N., Claros, A.F.F., Maldonado, C., Silman, M., Salinas, N., 835 Reynel, C., Neill, D.A., Serrano, M., Caballero, C.J., Cuadros, M.D.L., Macia, M.J., Killeen, T.J. 836 and Malhi, Y. (2014b) Spatial patterns of above-ground structure, biomass and composition in a 837 network of six Andean elevation transects. Plant Ecol. Divers. 7, 161-171.

838 Girardin, C.A.J., Malhi, Y., Aragao, L., Mamani, M., Huasco, W.H., Durand, L., Feeley, K.J., 839 Rapp, J., Silva-Espejo, J.E., Silman, M., Salinas, N. and Whittaker, R.J. (2010) Net primary 840 productivity allocation and cycling of carbon along a tropical forest elevational transect in the 841 Peruvian Andes. Glob. Chang. Biol. 16, 3176-3192.

842 Goldsmith, G.R., Matzke, N.J. and Dawson, T.E. (2013) The incidence and implications of 843 clouds for cloud forest plant water relations. Ecol. Lett. 16, 307-314.

844 Gonfiantini, R., Roche, M., Olivery, J., Fontes, J. and Zuppi, G. (2001) The altitude effect on the 845 isotopic composition of tropical rains. Chem. Geol. 181, 147-167. 
846 Gotsch, S.G., Asbjornsen, H., Holwerda, F., Goldsmith, G.R., Weintraub, A.E. and Dawson, T.E. 847 (2014) Foggy days and dry nights determine crown-level water balance in a seasonal tropical 848 montane cloud forest. Plant, Cell Envir. 37, 261-272.

849 Halladay, K., Malhi, Y. and New, M. (2012) Cloud frequency climatology at the Andes/Amazon 850 transition: 1. Seasonal and diurnal cycles. J. Geophys. Res.: Atmos. 117, D23102.

851 Horwath, A. (2011) Epiphytic Bryophytes as Cloud Forest Indicators: Stable Isotopes, Biomass 852 and Diversity along an Altitudinal Gradient in Peru. University of Cambridge, pp. 284.

853 Hou, J., D'Andrea, W. and Huang, Y. (2008) Can sedimentary leaf waxes record D/H ratios of 854 continental precipitation? Field, model and experimental assessments. Geochim. Cosmochimi. $855 \quad$ Acta 72, 3503-3517.

856 Hou, J.Z., D'Andrea, W.J., MacDonald, D. and Huang, Y. (2007) Hydrogen isotopic variability 857 in leaf waxes among terrestrial and aquatic plants around Blood Pond, Massachusetts, USA. Org. 858 Geochem. 38, 977-984.

859 Hren, M.T., Pagani, M., Erwin, D.M. and Brandon, M. (2010) Biomarker reconstruction of the 860 early Eocene paleotopography and paleoclimate of the northern Sierra Nevada. Geology 38, 786110.

862 Huacara Huasco, W., Girardin, C.A.J., Doughty, C.E., Metcalfe, D.B., Baca, L.D., Silva-Espejo, 863 J.E., Cabrera, D.G., Aragao, L., Davila, A.R., Marthews, T.R., Huaraca-Quispe, L.P., Alzamora864 Taype, I., Mora, L.E., Farfan-Rios, W., Cabrera, K.G., Halladay, K., Salinas-Revilla, N., Silman, 865 M.R., Meir, P. and Malhi, Y. (2014) Seasonal production, allocation and cycling of carbon in 866 two mid-elevation tropical montane forest plots in the Peruvian Andes. Plant Ecol. Divers. 7, $867 \quad 125-142$.

868 Jia, G.D., Wei, K., Chen, F.J. and Peng, P.A. (2008) Soil n-alkane delta D vs. altitude gradients 869 along Mount Gongga, China. Geochim. Cosmochim. Acta 72, 5165-5174. 
870 Kahmen, A., Hoffmann, B., Schefuß, E., Arndt, S.K., Cernusak, L.A., West, J.B. and Sachse, D. 871 (2013b) Leaf water deuterium enrichment shapes leaf wax n-alkane $\delta D$ values of angiosperm 872 plants II: Observational evidence and global implications. Geochim. Cosmochim. Acta 111, 5087363.

874 Kahmen, A., Schefuss, E. and Sachse, D. (2013a) Leaf water deuterium enrichment shapes leaf 875 wax n-alkane delta D values of angiosperm plants I: Experimental evidence and mechanistic 876 insights. Geochim. Cosmochim. Acta 111, 39-49.

877 Kreft, H. and Jetz, W. (2007) Global patterns and determinants of vascular plant diversity. Proc. 878 Natl. Acad. Sci. U. S. A. 104, 5925-5930.

879 Krull, E., Sachse, D., Mugler, I., Thiele, A. and Gleixner, G. (2006) Compound-specific d13C 880 and $\mathrm{d} 2 \mathrm{H}$ analyses of plant and soil organic matter: A preliminary assessment of the effects of 881 vegetation change on ecosystem hydrology. Soil Biol. Biochem. 38, 3211-3221.

882 Lavorel, S., Grigulis, K., McIntyre, S., Williams, N.S.G., Garden, D., Dorrough, J., Berman, S., 883 Quétier, F., Thébault, A. and Bonis, A. (2008) Assessing functional diversity in the field 884 methodology matters! Funct. Ecol. 22, 134-147.

885 Lee, J.E., Johnson, K. and Fung, I. (2009) Precipitation over South America during the Last 886 Glacial Maximum: An analysis of the "amount effect" with a water isotope-enabled general 887 circulation model. Geophys. Res. Lett. 36, L19701.

888 Li, S.G., Tsujimura, M., Sugimoto, A., Sasaki, L., Yamanaka, T., Davaa, G., Oyunbaatar, D. and 889 Sugita, M. (2006) Seasonal variation in oxygen isotope composition of waters for a montane 890 larch forest in Mongolia. Trees 20, 122-130.

891 Luo, P., Peng, P.A., Gleixner, G., Zheng, Z., Pang, Z.H. and Ding, Z.L. (2011) Empirical 892 relationship between leaf wax n-alkane delta D and altitude in the Wuyi, Shennongjia and 893 Tianshan Mountains, China: Implications for paleoaltimetry. Earth Planet. Sci. Lett. 301, 285894296. 
Malhi, Y., Amezquita, F.F., Doughty, C.E., Silva-Espejo, J.E., Girardin, C.A.J., Metcalfe, D.B., 896 Aragao, L., Huaraca-Quispe, L.P., Alzamora-Taype, I., Eguiluz-Mora, L., Marthews, T.R., 897 Halladay, K., Quesada, C.A., Robertson, A.L., Fisher, J.B., Zaragoza-Castells, J., Rojas-Villagra, 898 C.M., Pelaez-Tapia, Y., Salinas, N., Meir, P. and Phillips, O.L. (2014a) The productivity, 899 metabolism and carbon cycle of two lowland tropical forest plots in south-western Amazonia, 900 Peru. Plant Ecol. Divers. 7, 85-105.

Malhi, Y., Doughty, C.E., Goldsmith, G.R., Metcalfe, D.B., Girardin, C.A.J., Marthews, T.R., 902 del Aguila-Pasquel, J., Aragão, L.E.O.C., Araujo-Murakami, A., Brando, P., da Costa, A.C.L., 903 Silva-Espejo, J.E., Farfán Amézquita, F., Galbraith, D.R., Quesada, C.A., Rocha, W., Salinas904 Revilla, N., Silvério, D., Meir, P. and Phillips, O.L. (2015) The linkages between photosynthesis, 905 productivity, growth and biomass in lowland Amazonian forests. Glob. Chang. Biol. 21, 22839062295.

907 Malhi, Y., Gardner, T.A., Goldsmith, G.R., Silman, M.R. and Zelazowski, P. (2014b) Tropical 908 Forests in the Anthropocene. Ann. Rev. Envir. Res. 39, 125-159.

909 Malhi, Y., Silman, M., Salinas, N., Bush, M., Meir, P. and Saatchi, S. (2010) Introduction: 910 Elevation gradients in the tropics: laboratories for ecosystem ecology and global change 911 research. Glob. Chang. Biol. 16, 3171-3175.

912 Myers, N., Mittermeier, R.A., Mittermeier, C.G., da Fonseca, G.A.B. and Kent, J. (2000) 913 Biodiversity hotspots for conservation priorities. Nature 403, 853-858.

914 Newberry, S.L., Kahmen, A., Dennis, P. and Grant, A. (2015) n-Alkane biosynthetic hydrogen 915 isotope fractionation is not constant throughout the growing season in the riparian tree Salix 916 viminalis. Geochim. Cosmochim. Acta 165, 75-85.

917 Oyama, M.D. and Nobre, C.A. (2003) A new climate-vegetation equilibrium state for tropical 918 South America. Geophys. Res. Lett. 30. 
919 Paine, C.E.T., Baraloto, C. and Díaz, S. (2015) Optimal strategies for sampling functional traits 920 in species-rich forests. Funct. Ecol. 29, 1325-1331.

921 Pearson, A. and Eglinton, T. (2000) The origin of n-alkanes in Santa Monica Basin surface 922 sediment: a model based on compound-specific D14C and d13C data. Org. Geochem. 31, 11039231116.

924 Peterse, F., van der Meer, M.T.J., Schouten, S., Jia, G., Ossebaar, J., Blokker, J. and Damste, 925 J.S.S. (2009) Assessment of soil n-alkane delta $\mathrm{D}$ and branched tetraether membrane lipid 926 distributions as tools for paleoelevation reconstruction. Biogeosci. 6, 2799-2807.

927 Polissar, P.J. and Freeman, K.H. (2010) Effects of aridity and vegetation on plant-wax [delta]D 928 in modern lake sediments. Geochim. Cosmochim. Acta 74, 5785-5797.

929 Polissar, P.J., Freeman, K.H., Rowley, D.B., McInerney, F.A. and Currie, B.S. (2009)

930 Paleoaltimetry of the Tibetan Plateau from D/H ratios of lipid biomarkers. Earth Planet. Sci. 931 Lett. 287, 64-76.

932 Ponton, C., West, A.J., Feakins, S.J. and Galy, V. (2014) Leaf wax biomarkers in transit record 933 river catchment composition. Geophys. Res. Lett. 41, 6420-6427.

934 Porter, T.J., Froese, D.G., Feakins, S.J., Bindeman, I.N., Mahony, M.E., Pautler, B.G., Reichart, 935 G.-J., Sanborn, P.T., Simpson, M.J. and Weijers, J.W.H. (2016) Multiple water isotope proxy 936 reconstruction of extremely low last glacial temperatures in Eastern Beringia (Western Arctic). 937 Quat. Sci. Rev. 137, 113-125.

938 Rapp, J.M. and Silman, M.R. (2012) Diurnal, seasonal, and altitudinal trends in microclimate 939 across a tropical montane cloud forest. Clim. Res. 55, 17-32.

940 Sachse, D., Billault, I., Bowen, G.J., Chikaraishi, Y., Dawson, T.E., Feakins, S.J., Freeman, 941 K.H., Magill, C.R., McInerney, F.A., van der Meer, M.T.J., Polissar, P., Robins, R.J., Sachs, J.P., 942 Schmidt, H.-L., Sessions, A.L., White, J.W.C., West, J.B. and Kahmen, A. (2012) Molecular 
943 Paleohydrology: Interpreting the Hydrogen-Isotopic Composition of Lipid Biomarkers from

944 Photosynthesizing Organisms. Ann. Rev. Earth Planet. Sci. 40, 221-249.

945 Sachse, D., Radke, J. and Gleixner, G. (2004) Hydrogen isotope ratios of recent lacustrine 946 sedimentary n-alkanes record modern climate variability. Geochim. Cosmochim. Acta 63, 4877 9474889.

948 Sachse, D., Radke, J. and Gleixner, G. (2006) dD values of individual n-alkanes from terrestrial 949 plants along a climatic gradient - Implications for the sedimentary biomarker record. Org. 950 Geochem. 37, 469-483.

951 Salati, E., Dallolio, A., Matsui, E. and Gat, J.R. (1979) Recycling of water in the Amazon Basin 952 Isotopic study. Water Resour. Res. 15, 1250-1258.

953 Schefuss, E., Schouten, S. and Schneider, R. (2005) Climatic controls on central African 954 hydrology during the past 20,000 years. Nature 473, 1003-1006.

955 Sessions, A.L. (2006) Seasonal changes in D/H fractionation accompanying lipid biosynthesis in 956 Spartina alterniflora. Geochim. Cosmochim. Acta 70, 2153-2162.

957 Sessions, A.L., Burgoyne, T.W., Schimmelmann, A. and Hayes, J.M. (1999) Fractionation of 958 hydrogen isotopes in lipid biosynthesis. Org. Geochem. 30, 1193-1200.

959 Shanahan, T.M., Hughen, K.A., Ampel, L., Sauer, P.E. and Fornace, K. (2013) Environmental 960 controls on the $2 \mathrm{H} / 1 \mathrm{H}$ values of terrestrial leaf waxes in the eastern Canadian Arctic. Geochim. 961 Cosmochim. Acta 119, 286-301.

962 Silman, M.R. (2014) Functional megadiversity. Proc. Nat. Acad. Sci. U.S.A. 111, 5763-5764.

963 Smith, F. and Freeman, K. (2006) Influence of physiology and climate on dD of leaf wax n964 alkanes from C3 and C4 grasses. Geochim. Cosmochim. Acta 70, 1172-1187. 
965 Ter Steege, H., (2010) Contribution of current and historical processes to patterns of tree

966 diversity and composition of the Amazon, in: Hoorn, C., Wesselingh, F.P. (Eds.), Amazonia:

967 Landscape and Species Evolution. Wiley (Oxford), 349-359.

968 Tierney, J.E., Smerdon, J.E., Anchukaitis, K.J. and Seager, R. (2013) Multidecadal variability in 969 East African hydroclimate controlled by the Indian Ocean. Nature 493, 389-392.

970 Tipple, B.J., Berke, M.A., Doman, C.E., Khachaturyan, S. and Ehleringer, J.R. (2013) Leaf-wax $971 n$-alkanes record the plant-water environment at leaf flush. Proc. Nat. Acad. Sci. U.S.A. 110, $972 \quad 2659-2664$.

973 Tipple, B.J. and Pagani, M. (2013) Environmental control on eastern broadleaf forest species' 974 leaf wax distributions and D/H ratios. Geochim. Cosmochim. Acta 111, 64-77.

975 Viviroli, D., Dürr, H.H., Messerli, B., Meybeck, M. and Weingartner, R. (2007) Mountains of 976 the world, water towers for humanity: Typology, mapping, and global significance. Water 977 Resour. Res. 43, W07447.

978 West, J.B., Sobek, A. and Ehleringer, J.R. (2008) A Simplified GIS Approach to Modeling 979 Global Leaf Water Isoscapes. PLoS ONE 3, e2447.

980 Wilkie, K.M.K., Chapligin, B., Meyer, H., Burns, S., Petsch, S. and Brigham-Grette, J. (2013)

981 Modern isotope hydrology and controls on $\delta \mathrm{D}$ of plant leaf waxes at Lake El'gygytgyn, NE

982 Russia. Clim. Past 9, 335-352.

983 Winnick, M.J., Chamberlain, C.P., Caves, J.K. and Welker, J.M. (2014) Quantifying the isotopic 984 'continental effect'. Earth Planet. Sci. Lett. 406, 123-133.

985 Zelazowski, P., Malhi, Y., Huntingford, C., Sitch, S. and Fisher, J.B. (2011) Changes in the 986 potential distribution of humid tropical forests on a warmer planet. Phil. Trans. Royal Soc. A $987 \quad 369,137-160$. 
988 Zhou, Y.P., Grice, K., Stuart-Williams, H., Farquhar, G.D., Hocart, C.H., Lu, H. and Liu, W.G. 989 (2010) Biosynthetic origin of the saw-toothed profile in delta(13) C and delta H-2 of n-alkanes 990 and systematic isotopic differences between n-, iso- and anteiso-alkanes in leaf waxes of land 991 plants. Phytochem. 71, 388-403.

992 
992 Table 1. Environmental and ecological characteristics of 1-ha study plots along a tropical montane 993 elevation gradient.

\begin{tabular}{lccccc}
\hline CHAMBASA plot code & Tambopata 6 & Tambopata 5 & San Pedro 2 & San Pedro 1 & Esperanza \\
\hline RAINFOR site code & TAM-06 & TAM-05 & SPD-02 & SPD-01 & ESP-01 \\
Latitude & -12.8385 & -12.8309 & -13.0491 & -13.0475 & -13.1751 \\
Longitude & -69.2960 & -69.2705 & -71.5365 & -71.5423 & -71.5948 \\
Elevation $^{*}(\mathrm{~m})$ & 215 & 223 & 1494 & 1713 & 2868 \\
Slope $^{*}(\mathrm{deg})$ & 2.2 & 4.5 & 27.1 & 30.5 & 27.3 \\
Aspect $^{*}(\mathrm{deg})$ & 169 & 186 & 125 & 117 & 302 \\
Solar radiation $\left(\mathrm{GJ} \mathrm{m}^{-2} \mathrm{a}^{-1}\right)$ & 4.8 & 4.8 & 4.08 & 4.36 & $\mathrm{n} / \mathrm{a}$ \\
Mean annual air $_{\text {temperature }}^{* *}\left({ }^{\circ} \mathrm{C}\right)$ & 24.4 & 24.4 & 18.8 & 17.4 & 13.1 \\
Precipitation $(\mathrm{mm} \mathrm{a}$ & & 1900 & 5302 & 5302 & 1560 \\
Soil moisture $(\%)$ & 1900 & 21.8 & 37.3 & 37.6 & 24.3 \\
Vegetation height & 35.5 & 27.5 & 22.8 & 14.0 & 16.9 \\
\hline
\end{tabular}

994 "Derived from high-resolution airborne Light Detection and Ranging (LiDAR) data (see Asner et al. 2013

995 for methodology). ${ }^{* *}$ Derived from observations between 6 Feb 2013 and 7 Jan 2014.

996

997 


\section{Figure Legends}

998

999

1000

1001

1002

1003

1004

1005

1006

1007

1008

1009

1010

1011

1012

1013

1014

1015

1016

1017

1018

1019

1020

1021

1022

1023

1024

Fig. 1: Illustration of sample locations. See Appendix A for interactive map of sample location.

Fig. 2: Dual oxygen and hydrogen isotopic analysis of environmental and plant waters. (a) Meteoric waters including cloud water (grey circles), instantaneous precipitation samples (light blue circles; both Clark et al., 2014), biweekly integrations of precipitation (dark blue circles, LMWL) and stream waters differentiating wet and dry season (open and solid black squares respectively; both Ponton et al., 2014 and this study), with regressions. (b) Plant xylem (XW; orange diamonds) and leaf waters (LW; green triangles) both collected during the dry season, showing cloud and LMWL regressions from A for comparison. Inset: schematic of water sources and processes.

Fig. 3: Elevation gradients in plant xylem water (diamonds), leaf water (triangles) and leaf wax hydrogen isotopic composition (circles) (a) for the $\mathrm{C}_{28} n$-alkanoic acids and (b) for the $\mathrm{C}_{29} n$ alkanes. Data shown are for individual samples, which include mixed species with replicate sampling of each species (small symbols), regression line and statistics (for LW and XW see a). Also shown, site averages for each variable (large symbols). Note two sites TAM-05 and TAM06 are both very close to $0.2 \mathrm{~km}$ asl and therefore the two sites overlay at this elevation scale.

Fig. 4: Relationships between plant water $\delta \mathrm{D}$ and plant leaf wax $\delta \mathrm{D}$ values: (a) Xylem water vs. $n$-alkanoic acids, (b) leaf water vs. $n$-alkanoic acids, (c) xylem water vs. $n$-alkanes, and (d) leaf water vs. $n$-alkanes. Showing data for all homologues, regression lines only where relationships are significant. Xylem water is significantly correlated with leaf wax isotopic composition for all homologues with widespread presence; note that the longer chain $n$-alkanoic acids $\left(\mathrm{C}_{30}\right.$ and $\left.\mathrm{C}_{32}\right)$ are not found at the higher elevation sites (more negative $\delta \mathrm{D}_{\mathrm{Xw}}$ values). Leaf water is generally not significantly correlated with leaf wax isotopic composition (see text).

Fig. 5: Conceptual diagram showing tropical forest hydrogen isotope systematics, summarizing isotope-relevant fluxes (lines) fractionations (arrows) and compositions (boxes). The apparent fractionation $\varepsilon_{\text {app }}$ (dotted arrow) is a net effect and key to geological applications of the proxy, determined here directly as $\varepsilon_{\mathrm{wax} / \mathrm{Xw}}$ and $\varepsilon_{\mathrm{wax} / \mathrm{w}}$. Precipitation varies between storms and seasons but its time-averaged composition is reflected in xylem water. Leaf water may be enriched via 
transpiration but equilibration with atmospheric vapor at high relative humidity $(\mathrm{RH})$ and foliar uptake in the TMCF means the enrichment of leaf water over xylem water $\left(\varepsilon_{\mathrm{XW} / \mathrm{LW}}\right.$; dashed line) is minimal. Biosynthetic fractionation $\left(\varepsilon_{\text {bio }}\right)$ is the fractionation between substrate (water) and the product (wax) that occurs within the leaf and estimated by bulk leaf water measured at a single point in time (dry season, early afternoon) in this study $\left(\varepsilon_{\mathrm{wax} / \mathrm{LW}}\right)$. Modified after Sachse et al. (2006). Y-dimension denotes hydrogen isotopic composition. X-dimension denotes fluxes. Scaling and shading for illustrative purposes only. Inset: photo of tropical forest with cloud at foothills of the Andes taken at ca. $500 \mathrm{~m}$ asl.

Fig. 6: Apparent fractionations $\left(\varepsilon_{\mathrm{wax} / \mathrm{w}}\right)$ across the elevation transect, weighting for individual species contributions. a) Bubble plot weighing individual data for wax loading for $\mathrm{C}_{29} n$-alkane and (b) for $\mathrm{C}_{28} n$-alkanoic acid. (c) Summary plot showing mean unweighted values for all individuals, as well as weighted means that account for wax concentration of species and community-weighted means that account for both wax concentration and proportional species representation in each forest plot for $\mathrm{C}_{29} n$-alkane, and (d) for $\mathrm{C}_{28} n$-alkanoic acid. Overall unweighted mean apparent fractionation (black solid line, and $\pm 1 \sigma$ dotted lines) shown. (e) Community representation: fraction of basal area represented by sampling (pie charts), with number of individuals and species sampled.

Fig. 7: Elevation trends in $\delta \mathrm{D}$ values weighted for individual species contributions. (a) Bubble plot weighing individual data for wax loading for $\mathrm{C}_{28} n$-alkanoic acid and (b) for $\mathrm{C}_{29} n$-alkane. (c) Summary plot showing mean unweighted values for all individuals, as well weighted means that account for wax concentration of species and community-weighted means that account for both wax concentration and proportional species representation in the forest plot for $\mathrm{C}_{29} \mathrm{n}$ alkane, and (d) for $\mathrm{C}_{28} n$-alkanoic acid. The unweighted and weighted means are not significantly different. Error bars $(1 \sigma)$ and regression shown for the community-weighted means only. Regression is sensitive to the exclusion (solid line) or inclusion of SPD-01 outlier (open symbol, dashed line) as shown in (c).

Fig. 8: Tropical forest calibration using community-weighted plot mean $\delta \mathrm{D}$ values relative to source water $\delta \mathrm{D}$ values for both the $\mathrm{C}_{29} n$-alkane (red) and the $\mathrm{C}_{28} n$-alkanoic acid (gold), excluding one outlier (SPD-01 $\mathrm{C}_{28} n$-alkanoic acid) as in Fig. 7. Ordinary least squares regression 
1054 (solid line), 95\% confidence intervals (dashed line), extrapolation (dotted line) to intercept

$1055\left(\varepsilon_{\mathrm{wax} / \mathrm{w}}\right)$. Relationship of slope and intercept is in the form $\mathrm{y}=\alpha \mathrm{x}+\varepsilon$, and within uncertainties

1056 meets expectations that $\alpha=1-\varepsilon$ (from Eq. 1) as well as being similar to $\varepsilon_{\mathrm{wax} / \mathrm{w}}$ or $\varepsilon_{\mathrm{wax} / \mathrm{XW}}$

1057 calculated as the average of individuals (Appendix A). 


\section{Tropical}

Montane SPD-01,1.7km asl, above cloud base Cloud Forest SPD-02, 1.5km asl, below cloud base

Tropical Rainforest

W

\author{
$0.2 \mathrm{~km}$ asl \\ TAM-05 TAM-06
}

river-distal river-proximal 

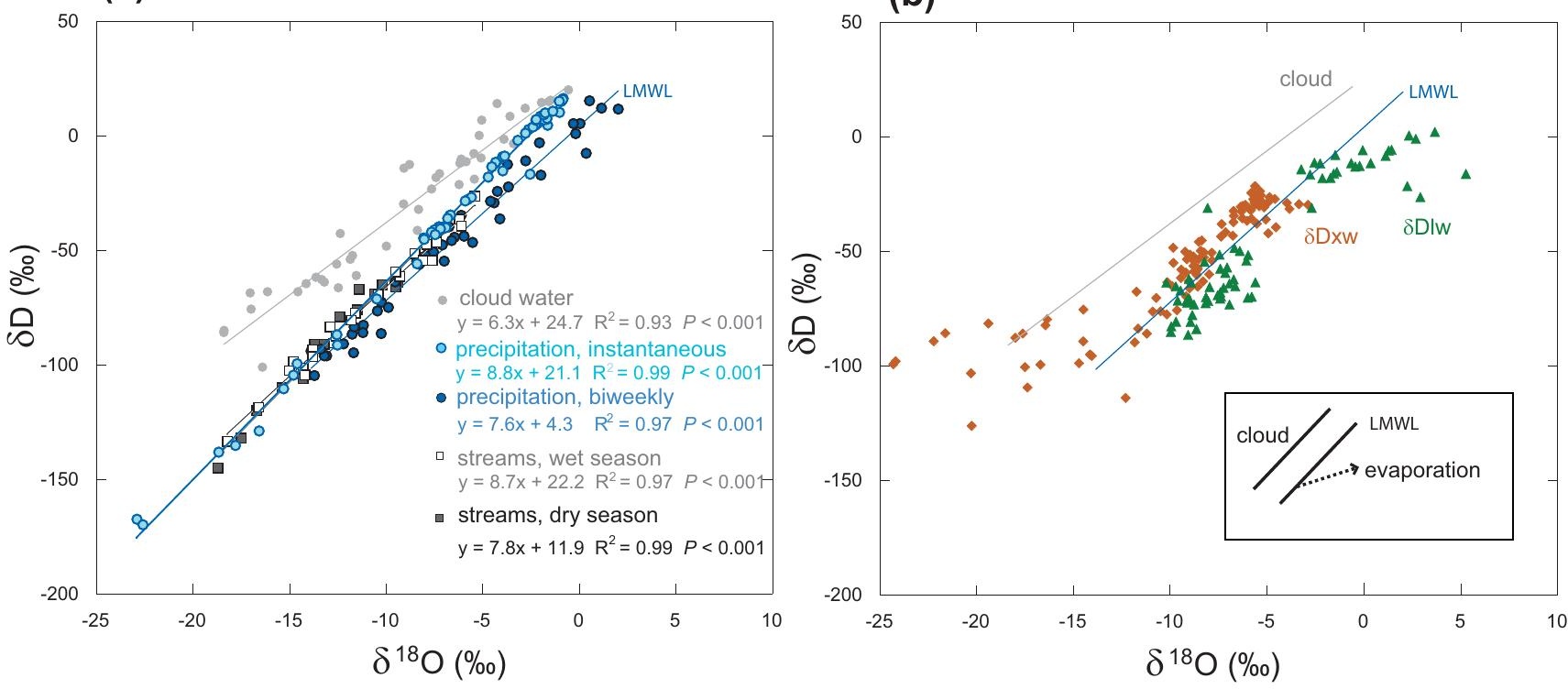


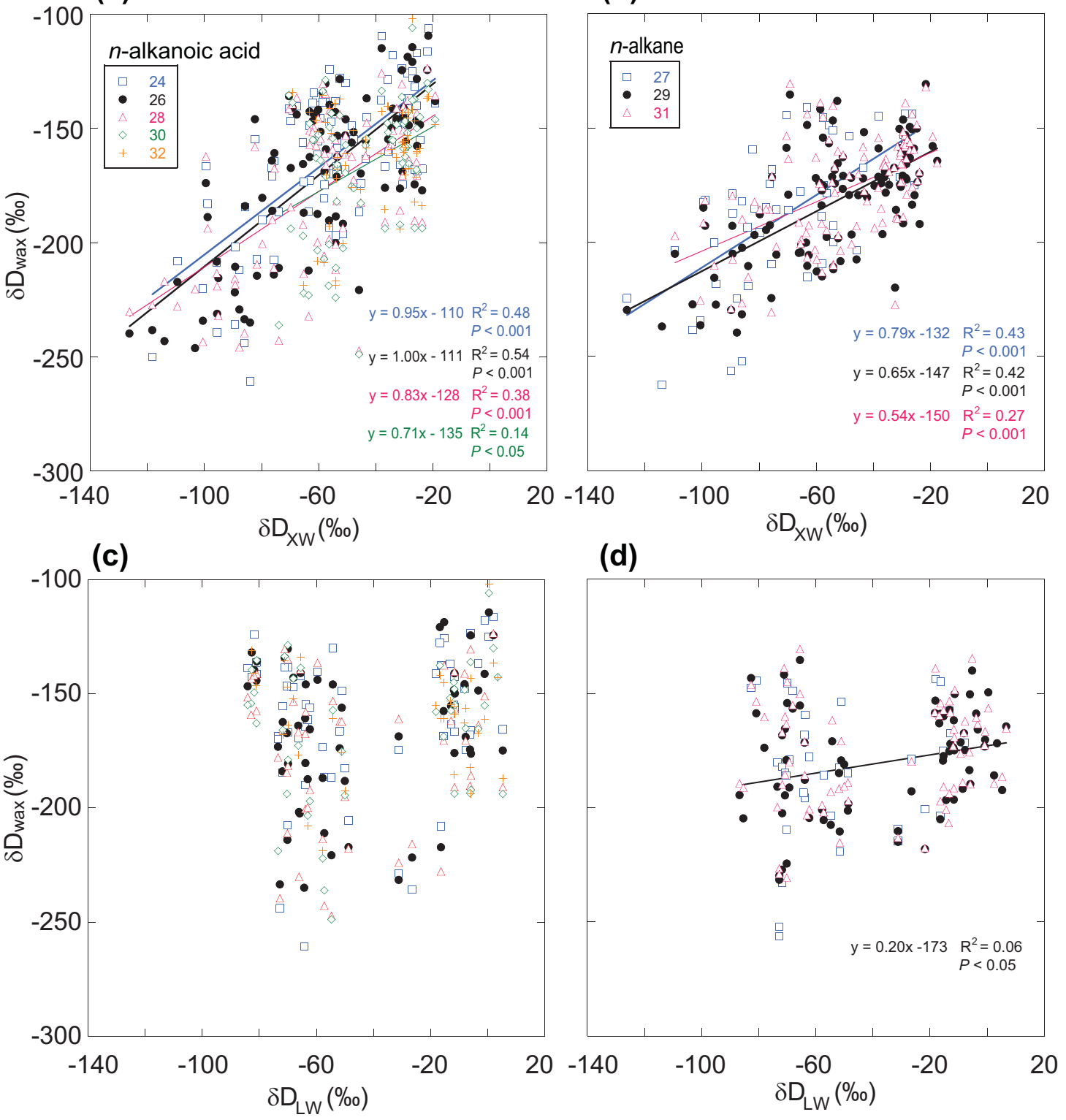


Hydrogen isotope systematics in a moist tropical forest

$+\delta \mathrm{D}$

$\varepsilon_{\mathrm{LW} / \mathrm{XW}}<20 \%$

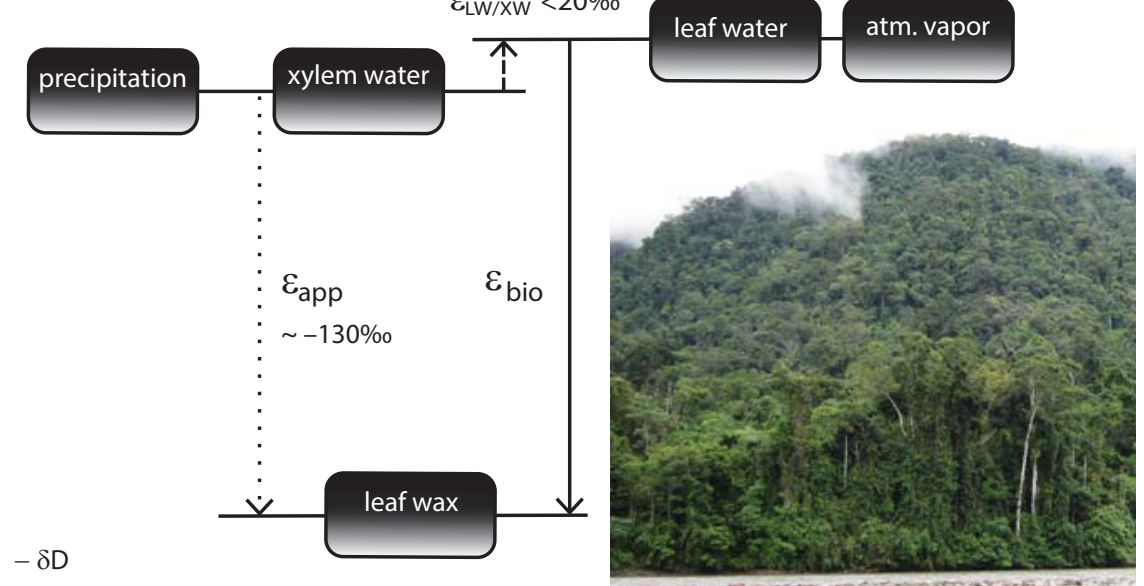




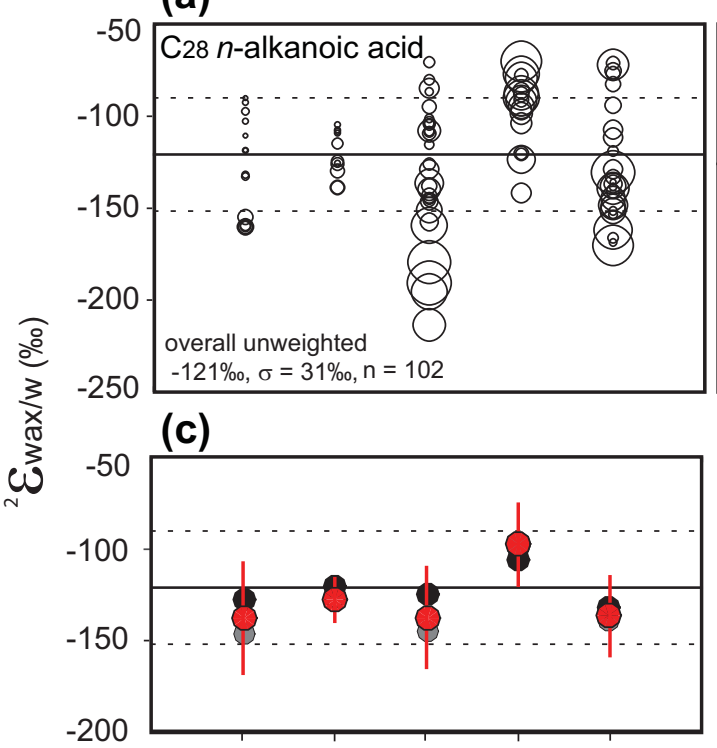

Site:TAM-06 TAM-05 SPD-02 SPD-01 ESP-01

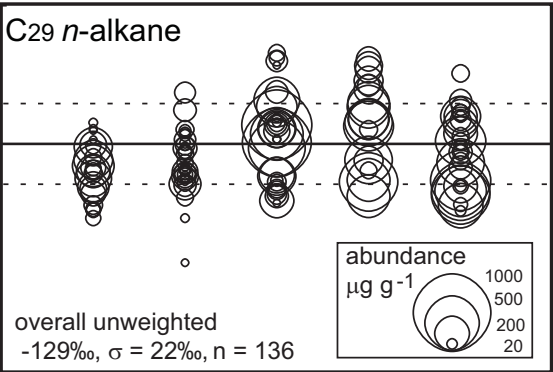

(d)

unweighted 0 concentration-weighted only community-weighted (conc. \& basal area)

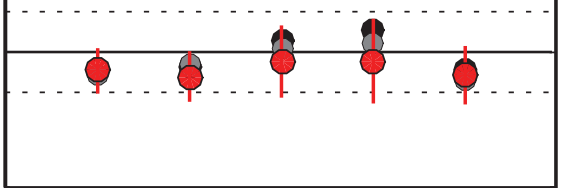

TAM-06 TAM-05 SPD-02 SPD-01 ESP-01

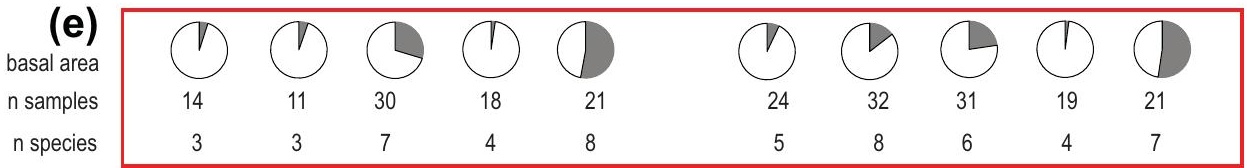




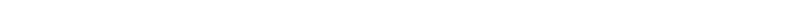

